\title{
Evaluation of a DSGE Model of Energy in the United Kingdom Using Stationary Data
}

\author{
Nasir Aminu ${ }^{1}$
}

Accepted: 20 January 2017 / Published online: 9 February 2017

(C) The Author(s) 2017. This article is published with open access at Springerlink.com

\begin{abstract}
I examine the impact of energy price shock (oil prices shock and gas prices shock) on the economic activities in the United Kingdom using a dynamic stochastic general equilibrium model with a New Keynesian Philips Curve. I decomposed the changes in output caused by all of the stationary structural shocks. I found that the fall in output during the financial crisis period is driven by domestic demand shock, energy prices shock and world demand shock. I found the energy prices shock's contribution to fall in output is temporary. Such that, the UK can borrow against such a temporary fall. This estimated model can create additional input to the policymaker's choice of models.
\end{abstract}

Keywords Energy price · DSGE · Output

\section{Introduction}

This aim of this paper is to investigate the effects of energy prices shocks on economic activities in the United Kingdom (UK) with filtered data. The decline in the energy prices has positive significant impacts in reducing costs in energy intensive sectors such as transportation and manufacturing. Declining energy prices are also favourable

This work is done under the supervision of Professor Patrick Minford and Dr David Meenagh, Cardiff Business School, Cardiff University, Aberconway Building, Colum Drive, Cardiff, CF10 3EU, UK. I thank them all. I also extend Professor Stephen Millard, Bank of England for giving me more information on his model and data construction.

$凶 \quad$ Nasir Aminu

naminu@cardiffmet.ac.uk

1 Cardiff School of Management, Cardiff Metropolitan University, Western Avenue, Llandaff, Cardiff CF5 5YB, UK 
to economies that are importers and net-importers of oil, such as the UK, China, India and Japan. However, it is bad news for oil dependent economies, such as Nigeria, Venezuela, and Kuwait. The second quarter, the months of March to June, of 2015 UK CPI report showed that inflation in the energy intensive sectors fell by $1.8 \%$. However, energy prices have fluctuated significantly in the past decade. A good example is that it took only 5 months, from July 2014 to December 2014, for the price of crude oil to fall from about $\$ 100$ a barrel to $\$ 52$ a barrel. Crude oil prices also fell from about $\$ 150$ a barrel in 2008Q1 to under $\$ 40$ a barrel in 2009Q1. Conversely, oil prices quickly reversed course, climbed steadily and reached more than $\$ 75$ a barrel in 2009. Such sequence of phenomena is what pushes for empirical research and application of theoretical work.

Millard (2011) estimated an energy model in the UK using the Bayesian method. However, he found that energy price shocks (oil prices and gas prices) have little effect on the variability of output and inflation. His findings are consistent with Harrison et al. (2011). Few other authors used dynamic stochastic general equilibrium (DSGE) model to study the UK economy, such as Harrison and Oomen (2010) and Faccini et al. (2011). They develop models of inflation, built around the 'New Keynesian Phillips Curve' (NKPC), to imply how inflation depends on lagged inflation, expected future inflation and the real marginal cost. In these models, real marginal cost will also be equivalent to real unit labour costs, although, as shown by Faccini et al. (2011) and Kamber and Millard (2010), since energy and labour are complementary inputs to production, the real marginal cost is affected by changes in energy prices. Therefore, movements in energy prices will be significant for inflation. Since consumers are also users of energy, any shift in energy prices will have a direct impact on CPI inflation, which is not impacted by the NKPC. As oil prices rise, central banks expect to tighten monetary policy. Borrowing rate expect to increase since investors demand higher interest rates, with an expectation of higher inflation. However, I did not find empirical evidence of Bank of England, like the Federal Reserve, responding to rising energy prices in the past. In the past 30 years, a large body of research tried to examine the effects that oil prices shocks have had on the macroeconomy. Studies, on oil prices shock, (Bernanke et al. 1997; Kilian 2008; Hamilton 2009) found that these shocks seem to have a lesser effect on output, interest rates and inflation during the great moderation period. As Nordhaus (1980) puts it, the fundamental logic of energy policy is to lower demand of energy, in order, to have lower terms of trade losses and, thereby, higher real income in the economy.

Kim and Loungani (1992) and Finn (1995) study the significance of energy price shocks using closed economy real business cycle (RBC) models, with an emphasis on the United States. They find that energy prices shock can provide little significance in explaining the real macroeconomic aggregate fluctuations in the economy. Conversely, the study of Miguel et al. (2003) finds that where they proposed a small open economy RBC model, the oil price shocks are highly significant in explaining aggregate fluctuations. Their results show that oil prices shocks can explain a significant percentage of output fluctuations in many southern European countries. Their models also replicate the cyclical path of the periods of oil crisis in the European economies. The rise in the relative price of oil had a negative impact on welfare, mostly in the 
southern European countries, which historical data relates to a lax monetary policy in oil crisis periods.

In this paper, I present how a dynamic stochastic general equilibrium (DSGE) model, that unusually incorporates energy sector, is set up. The model, like many macroeconomic models, aims to capture some aspects of reality of macroeconomic aggregates in the economy from optimizing behaviour at individual level. These aspects of reality include how monetary policy changes feed through the economy and what drives inflation in the economy. This is because no single model, yet, has been able to capture all aspects of reality in an economy. I explain the estimation technique and how it is carried out, and assessed the fit of the model using indirect inference testing. I also show how the model works by impulse response functions ${ }^{1}$ (IRF), vector autoregressive impulse response functions (VAR-IRF). I then discuss the estimation result by variance decomposition and analyse what the model says about energy price shocks by giving a timeline of the crisis period.

\section{The Model}

The model I propose closely follows that of Millard $(2011)^{2}$ that evaluated a DSGE model of energy in the UK using a Bayesian estimation method. The key feature of the model is the firm's incorporation of energy inputs in the production function as well as intermediate imported goods. The UK economy, in this study, is characterized as a small open economy and also a primary producer of crude oil and gas (energy). This assumption may not be a reality since the production of oil and gas in the UK is in decline according to Webb (2013). The UK is a currently a net importer of oil and will continue for the next 20 years by about $75 \%$. The continuous decline of energy resource extraction is likely to particularly effect domestic consumption and the exchange rate since energy prices will be changing permanently. As a result, it will have implications on the UK monetary policy.

Figure 1 shows how investment accumulates into the capital stock. It shows how the capital $(\mathrm{K})$, capital utilisation rate $(\mathrm{z})$ and labour hours $(\mathrm{h})$ are pooled to produce value added (V). This is considered to be output in the model, I use the Gross Value Added (GVA) to represent output in this study. Value added is distributed to the three producing firms: the non-energy goods sector $\left(\mathrm{V}_{\mathrm{n}}\right)$; the utilities sector $\left(\mathrm{V}_{\mathrm{u}}\right)$; and petrol sector $\left(\mathrm{V}_{\mathrm{p}}\right)$. Value added is used with other inputs to produce other types of goods. The petrol sector uses value added $\left(\mathrm{V}_{\mathrm{p}}\right)$ and oil $(\mathrm{O})$ to produce petrol $\left(\mathrm{q}_{\mathrm{p}}\right)$. The amount of crude oil used in UK petrol production is the total of the UK's endowment of oil $(\bar{O})$ and net trade in oil with the rest of the world $\left(\mathrm{X}_{\mathrm{O}}\right)$. The utilities sector also uses value added $\left(\mathrm{V}_{\mathrm{u}}\right)$ and gas $(\overline{\mathrm{G}})$ to produce the utilities output $\left(\mathrm{q}_{\mathrm{u}}\right)$ and the amount of gas combined in production comes from the endowment $(\overline{\mathrm{G}})$ and net trade with the rest of the world $\left(\mathrm{X}_{\mathrm{g}}\right)$. The energy output (including petrol and utilities) is combined with value added $\left(\mathrm{V}_{\mathrm{n}}\right)$ and intermediate imports $(\mathrm{M})$ to produce the final output $(\mathrm{q})$ of non-energy. The final output is referred as non-energy gross output in this study, this

\footnotetext{
1 See "Appendix 1".

2 For full version of the model, see "Appendix 2".
} 


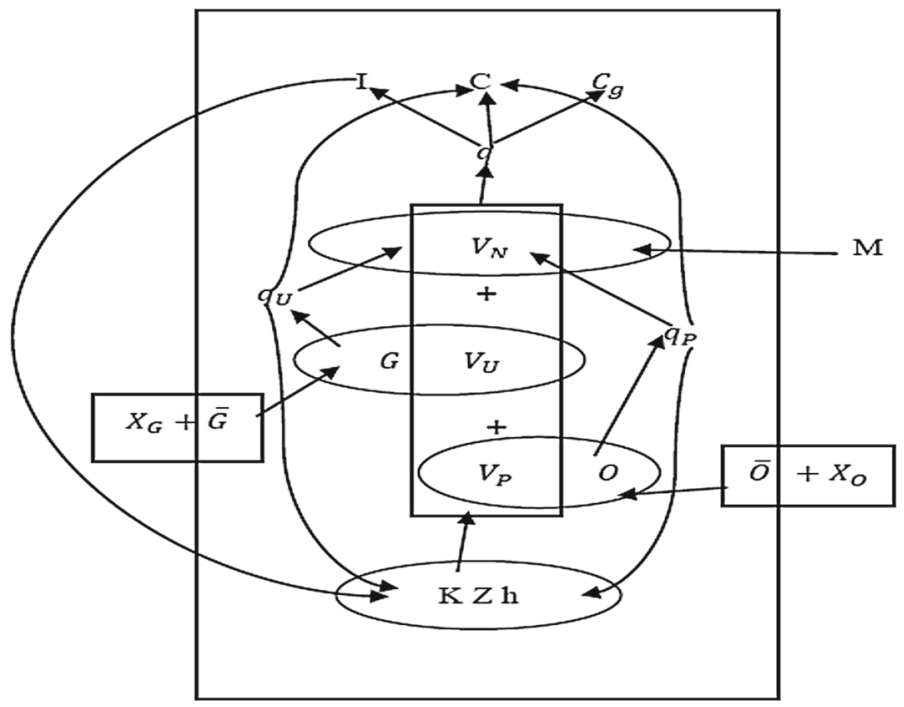

Fig. 1 Model diagram

is more or less the gross domestic product (GDP) less energy sector, I use the volume of the final output of the private non-oil and gas extraction sector to represent $(\mathrm{q})$ in this study. This non-energy gross output is traded to households for consumption (C), for investment $(\mathrm{I})$, to government $\left(\mathrm{C}_{\mathrm{g}}\right)$ and to the rest of the world as exports $(\mathrm{X}) .^{3}$

\section{Methodology}

\subsection{Model Evaluation by Indirect Inference}

Since the revolutionary ideas of Kyland and Prescott's 1982 seminal paper, economists have found the passion to take business cycle models to data. The model's parameters ${ }^{4}$ are calibrated, first, then used to produce simulated data that matches the actual data (Rebelo 2005), by estimation. I use the powerful simulated annealing algorithm ${ }^{5}$ to estimate the model's parameters to get the model as close as possible to the data. I adopt the approach of sampling variability of the simulated data to match the actual data using indirect inference testing. This is in contrast to indirect inference estimation.

Indirect inference test method of model evaluation offers a classical econometrics inferential structure for assessing calibrated models. Minford et al. (2009) first proposed the method, Le et al. (2012) augmented the methodology as is widely used.

\footnotetext{
3 The model closely follows Harrison et al. (2011) graphical description, but not quantitatively.

4 Please see "Appendix 3".

5 I use a simulated annealing algorithm due to Ingber (1996). This mimics the feature of the steel cooling process, with a degree of reheating at randomly chosen moments in the cooling process which ensures that the defects are minimised globally.
} 
This method is used to judge partially or fully estimated models while maintaining the fundamental ideas utilized in the evaluation of early RBC models of comparing data generated moments from the model simulation by the actual data. Instead of using moments to compare with no distributions, this method provides a simple model (auxiliary model) that includes the conditional mean of the distribution which one can compare the features of the model estimated from actual and simulated data. This, indirect inference test, the method on structural DSGE models, although different, has similar features in the widely used indirect estimation method. The primary feature of this similarity is utilization of the auxiliary model in addition to the structural macroeconomic model. The estimation by indirect inference chooses the parameters of the DSGE model in a way that the simulated model generates estimates of the auxiliary model that is similar to those obtained from the data.

Le et al. (2013) found that using indirect inference is useful when identification is in doubt. Their numerical procedure found the DSGE model study of Smets and Wouters (2003) to be over-identified and a three equation New Keynesian model similar to Clarida, Gali and Gertler (1999) was identified. Their result agrees with the findings of Canova and Sala (2009). Therefore, the indirect inference testing method will ensure identification because the model I use is a linearized model where local and global identification coincide.

An account of inferential problem, applying Canova (2005) representations proposed for indirect inference estimation, where $y_{t}$ is defined as $m \times 1$ vector observed data $(t=1, \ldots, T)$ and $x_{t}(\theta)$ is a $m \times 1$ vector of simulated (time series) data with the number of observations $S$ which is generated from the structural model, $\theta$ is a $k \times 1$ vector of the model's structural parameters. The assumption here is that $y_{t}$ and $x_{t}(\theta)$ are stationary and ergodic. Then set $S=T$ with the requirement of the actual data sample being regarded as the expected imitation from the population of the samples that have been bootstrapped by the data. The auxiliary model is assumed as $f\left(y_{t}, \alpha\right)$, with $\alpha$ as the vector of descriptors. From the given null hypothesis $H_{0}: \theta=\theta_{0}$, the auxiliary model then becomes $f\left[x_{t}(\theta),\left(\theta_{0}\right)\right]=$ as $f\left[y_{t}, \alpha\right]$. The test of the null hypothesis is by a $q \times 1$ vector of a continuous function $g(\alpha)$. Therefore, under the null hypothesis, one is going to have $g(\alpha)=g\left(\alpha\left(\theta_{0}\right)\right)$. The estimator for $\alpha$ using the actual data is $a_{T}$ while the estimator for $\left(\theta_{0}\right)$ based on simulated data is $a_{S}\left(\theta_{0}\right)$, where it gives us $g\left(a_{T}\right)$ and $g\left(a_{S}\left(\theta_{0}\right)\right)$. I derived the mean of the bootstraps by: $\overline{g\left(\alpha\left(\theta_{0}\right)\right)}=\frac{1}{N} \sum_{k=1}^{N} g_{k}\left(\alpha\left(\theta_{0}\right)\right)$. From here, we get the Wald statistic (WS) by using the bootstrapped distribution of $g\left(a_{S}\right)-\overline{g\left(a_{S}\left(\theta_{0}\right)\right)}$. This is then defined as:

$$
W S=g\left(a_{T}\right)-\overline{g\left(a_{S}\left(\theta_{0}\right)\right)^{\prime}} W\left(\theta_{0}\right)^{-1}\left(\theta_{0}\right) g\left(a_{T}\right)-\overline{g\left(a_{S}\left(\theta_{0}\right)\right)}
$$

where $W\left(\theta_{0}\right)$ is the variance-covariance of the bootstrapped distribution of $g\left(a_{S}\right)$ $\overline{g\left(a_{S}\left(\theta_{0}\right)\right)}$. Furthermore, $W\left(\theta_{0}\right)$ is obtained from the asymptotic distribution of $g\left(a_{S}\right)-\overline{g\left(a_{S}\left(\theta_{0}\right)\right)}$ and then the asymptotic distribution of the Wald statistic would then be chi-squared. Unlike the above, with an indirect inference test one will obtain an empirical distribution of the Wald statistic bootstrap using a bootstrap method through defining $g(\alpha)$ as a vector consisting of the vector autoregressive (VAR) coefficients and the variances of the data or the disturbances of the VAR model. 


\section{Results Analysis}

Using the method above, I employ stationary data of the UK to apply the model. Before I assess the fit of the model, I discuss how the Wald test by bootstrap is conducted:

Step 1 Estimating the errors of the structural model based on observed data and $\theta_{0}$.

The number of exogenous shocks must be equal to or less than the endogenous variables in the DSGE model. I estimate the 12 structural residuals ${ }^{6} \varepsilon_{\mathrm{j}, \mathrm{t}}$ from the model

6 The 12 structural residuals are estimated from the structural equations of the model, see Millard (2011): Consumption Euler equation

$$
\begin{aligned}
\hat{c}_{t}= & \frac{\psi_{h a b}\left(1-\sigma_{c}\right)}{1+\psi_{h a b}\left(1-\sigma_{c}\right)} \hat{c}_{t-1}+\frac{1}{1+\psi_{h a b}\left(1-\sigma_{c}\right)} E_{t} \hat{c}_{t+1} \\
& -\frac{\sigma_{c}}{1+\psi_{h a b}\left(1-\sigma_{c}\right)}\left(i_{t}-E_{t} \pi_{c, t+1}-\left(\frac{1}{\beta}-1\right)+\varepsilon_{b, t}\right)
\end{aligned}
$$

Capital Stock equation

$$
\begin{aligned}
\left(i_{t}-E_{t} \pi_{c, t+1}-\left(\frac{1}{\beta}-1\right)+\varepsilon_{b}\right)= & \left(\frac{\varepsilon_{k}}{1-\delta+\chi_{z}}+\left(1+\varepsilon_{k}\right)\right) \chi_{k} \hat{k}_{t-1}-\left(\frac{\left(1+\varepsilon_{k}\right)}{1-\delta+\chi_{z}}+1\right) \chi_{k} \hat{k}_{t} \\
& +\frac{\chi_{k}}{1-\delta+\chi_{z}} E_{t} \hat{k}_{t+1}-\chi_{k} \varepsilon_{k} \hat{k}_{t-2}+\frac{\chi_{k}}{1-\delta+\chi_{z}} E_{t} \hat{w}_{k, t+1}+\varepsilon_{\text {inv }, t}
\end{aligned}
$$

Foreign Bonds preference, UIP condition

$$
E_{t} \hat{s}_{t+1}-\hat{s}_{t}=-\left(i_{t}-\left(\frac{1}{\beta}-1\right)\right)+\chi_{b f} b_{f, t}+\varepsilon_{r f, t}
$$

Wage Mark-up

$$
\begin{aligned}
\dot{W}_{t}= & \frac{\xi_{w}}{1+\beta \xi_{w}} \dot{W}_{t-1}+\frac{\beta}{1+\beta \xi_{w}} E_{t} \dot{W}_{t+1} \\
& -\left(\frac{\psi_{w}\left(1-\beta\left(1-\psi_{w}\right)\right)}{\left(1+\frac{\sigma_{w}}{\sigma_{h}}\right)\left(1-\psi_{w}\right)\left(1+\beta \xi_{w}\right)}\right)\left(\hat{w}_{t}-m r s_{t}\right)+\varepsilon_{w, t}
\end{aligned}
$$

Non-energy gross output and price mark-up, respectively

$$
\begin{aligned}
& \hat{q}_{t}=\left(1-\alpha_{q}\right) \hat{B}_{t}+\alpha_{q} \hat{e}_{t}+\varepsilon_{q, t} \\
& \pi_{t}=\frac{\beta}{(1+\beta \varepsilon)} E_{t} \pi_{t+1}+\frac{\varepsilon}{(1+\beta \varepsilon)} \pi_{t-1}+\frac{\left(1-\chi_{p}\right)\left(1-\beta \chi_{p}\right)}{(1+\beta \varepsilon) \chi_{p}} \hat{\mu}_{t}+\varepsilon_{\mu, t}
\end{aligned}
$$

Monetary policy

$$
i_{t}-\left(\frac{1}{\beta}-1\right)=\theta_{r g}\left(i_{t-1}-\left(\frac{1}{\beta}-1\right)\right)+\left(1-\theta_{r g}\right)\left(\theta_{p d o t} \pi_{c, t}+\theta_{y} \hat{y}_{t}\right)+\varepsilon_{i, t}
$$

World oil and gas prices:

$$
\begin{aligned}
& \hat{\mathrm{p}}_{\mathrm{o}, \mathrm{t}}=\varepsilon_{\mathrm{p}_{\mathrm{o}}, \mathrm{t}}+\hat{\mathrm{s}}_{\mathrm{t}} \\
& \hat{\mathrm{p}}_{\mathrm{g}, \mathrm{t}}=\varepsilon_{\mathrm{pg}, \mathrm{t}}+\hat{\mathrm{s}}_{\mathrm{t}}
\end{aligned}
$$


$x_{t}\left(\theta_{0}\right)$, given the stated values of $\theta_{0}$ using the observed data of each variable in the equation. I used the assumption that the errors are be normally distributed and follow autoregressive $\mathrm{AR}(1)$ process. Where the structural equation contains no expectation, the residuals may be backed out of the equation and the observed data. If the equation includes some expectations on some variables, then there will be estimation for the expected variables. In this case, I carry this out using McCallum (1976) and Wickens (1982) a robust instrumental variables method with lagged endogenous observed data as the instruments. This is more or less an auxiliary model VAR.

Step 2 Deriving the simulated data

In this model, like many DSGE models, the structural shocks are assumed to be autoregressive processes rather than being serially independent. OLS is used to estimate the innovations from the residuals. ${ }^{7}$ The innovations are repeatedly drawn by time vector to preserve any simultaneity between the shocks, and then solving the model by dynare. I then go on to obtain $\mathrm{N}$ bootstrapped simulations by repeating the drawing of the sample independently. $\mathrm{N}=1000$ (Figs. 2, 3, 4, 5).

Step 3 Compute the Wald Statistic

The auxiliary model is then estimated, a $\operatorname{VAR}(1)$, on the bootstrap sample and the actual data to obtain the estimates, ${ }^{8}$ of the distribution of the observed data and the VAR coefficients, $\mathrm{a}_{\mathrm{T}}$ and as of the vector $\alpha$. I am able to obtain the covariance matrix $\mathrm{W}\left(\theta_{0}\right)$ of the distribution (as) $\overline{\left(\mathrm{a}_{\mathrm{S}}\left(\theta_{0}\right)\right)}$ through estimating the auxiliary VAR on the 1000 bootstrapped simulations of as $\left(\theta_{0}\right)$ while the covariance of the simulated variables from the bootstrap samples were obtained. This shows the variations in the data sampling as implied by the model from the result set of $\mathrm{a}_{\mathrm{k}}$ vectors $(\mathrm{k}=1, \ldots \mathrm{N})$, thus the estimate of $\mathrm{W}\left(\theta_{0}\right)$ will be:

$$
\frac{1}{\mathrm{~N}} \sum_{\mathrm{k}=1}^{\mathrm{N}}\left(\mathrm{a}_{\mathrm{k}}-\overline{\mathrm{a}_{\mathrm{k}}}\right)^{\prime}\left(\mathrm{a}_{\mathrm{k}}-\overline{\mathrm{a}_{\mathrm{k}}}\right)
$$

Footnote 6 continued

NKPC for UK import prices

$\pi_{m, t}=\frac{l_{p m}}{\left(1+\beta l_{p m}\right)} \pi_{m, t-1}+\frac{\beta}{\left(1+\beta l_{p m}\right)} E_{t} \pi_{m, t+1}+\frac{\left(1-\xi_{p m}\right)\left(1-\beta \xi_{p m}\right)}{\left(1+\beta l_{p m}\right) \xi_{p m}}\left(\varepsilon_{p_{m f}, t}-\hat{s}_{t}-\hat{p}_{m t}\right)$

World demand:

$$
\begin{aligned}
\hat{x}_{n, t} & =\psi_{z} \hat{x}_{n, t-1}-\psi_{z}\left(\eta_{x} \hat{s}_{t}\right)+\varepsilon_{y f} \\
\hat{q}_{t} & =\frac{c_{n}}{q} \hat{c}_{n, t}+\frac{k}{q} \hat{k}_{t}-\frac{(1-\delta) k}{q} \hat{k}_{t-1}+\frac{\chi_{z} k}{q} \hat{z}_{t}+\frac{x_{n}}{q} \hat{x}_{n, t}+\varepsilon_{g, t} .
\end{aligned}
$$

7 The coefficients of the residuals from the OLS estimation are the model's persistence.

8 Actual and simulated data variances have been included in the estimates to determine the model's dynamics and volatility. 

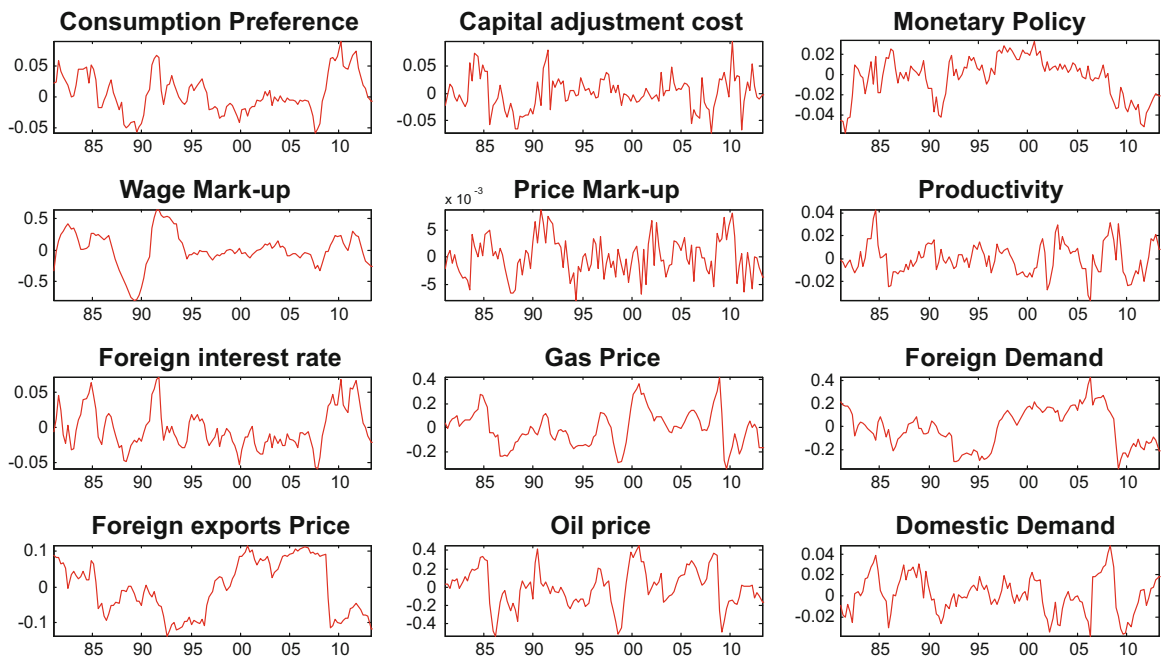

Fig. 2 Estimated structural residuals

where $\overline{\mathrm{a}_{\mathrm{k}}}=\frac{1}{\mathrm{~N}} \sum_{\mathrm{k}=1}^{\mathrm{N}} \mathrm{a}_{\mathrm{k}}$. From here, the Wald statistic is calculated for the data sample and then the bootstrap distribution of the Wald from the 1000 samples of the bootstrap is assessed.

\subsection{Assessing the Fit of the Estimated Model}

The indirect inference test is based on the significant comparison of the actual data with the simulated data from the structural model that comes through an auxiliary model. The test is based on the VAR coefficients and the data variances of the variables in the VAR.

$$
\left[\begin{array}{l}
\mathrm{y}_{\mathrm{t}} \\
\pi_{\mathrm{t}} \\
\mathrm{r}_{\mathrm{t}}
\end{array}\right]=\left[\begin{array}{lll}
\beta_{11} & \beta_{21} & \beta_{31} \\
\beta_{12} & \beta_{22} & \beta_{32} \\
\beta_{13} & \beta_{23} & \beta_{33}
\end{array}\right]\left[\begin{array}{l}
\mathrm{y}_{\mathrm{t}-1} \\
\pi_{\mathrm{t}-1} \\
\mathrm{r}_{\mathrm{t}-1}
\end{array}\right]+\Omega_{\mathrm{t}}
$$

A combination of output $(y)$, Inflation rate $(\pi)$ and real interest rate $(r)$ were chosen as the auxiliary model of VAR, for the evaluation to fit the model although other combinations were used, this set was used in the estimation as the variables in the VAR auxiliary model. The descriptors provide a strong argument for the structural model to match.

Using the method of indirect inference testing to test and estimate the model, I use $\operatorname{VAR}(1)$ as the auxiliary model. A VAR $(1)^{9} \alpha$ contains 12 elements, that is 9 VAR coefficients and 3 variances of the actual data used. The model is tested using the

\footnotetext{
9 Increasing the VAR order will increase the VAR coefficients. VAR(2) will generate 18 VAR coefficients which will make 21 elements in total, making it difficult to match the data. VAR(1) was chosen and it proves to be effective.
} 
Table 1 Summary of VAR results

\begin{tabular}{lccc}
\hline $\begin{array}{l}\text { Variables used in testing: output, } \\
\text { inflation and interest rate }\end{array}$ & Normalized T-statistic & Wald (\%) & $p$ value \\
\hline Dynamics & 9.4939 & 100 & 0.00 \\
Dynamics and volatility & 13.5826 & 100 & 0.00 \\
Volatility & 9.7516 & 100 & 0.00 \\
\hline
\end{tabular}

Table 2 VAR results

\begin{tabular}{|c|c|c|c|c|}
\hline Categories & $95 \%$ lower & $95 \%$ upper & Actual & IN/OUT \\
\hline$A_{y}^{y}$ & 0.459416 & 0.773121 & 0.933917 & OUT \\
\hline$A_{y}^{\pi}$ & -0.656821 & 0.273008 & -0.054771 & IN \\
\hline$A_{y}^{r}$ & -0.512248 & 0.098587 & -0.062042 & IN \\
\hline$A_{\pi}^{y}$ & 0.022581 & 0.125566 & 0.107079 & IN \\
\hline$A_{\pi}^{\pi}$ & 0.666408 & 0.885087 & 0.810838 & IN \\
\hline$A_{\pi}^{r}$ & -0.034367 & 0.136235 & -0.093553 & OUT \\
\hline$A_{r}^{y}$ & -0.031974 & 0.087848 & 0.151025 & OUT \\
\hline$A_{r}^{\pi}$ & -0.086830 & 0.257084 & 0.190834 & IN \\
\hline$A_{r}^{r}$ & 0.768280 & 0.987982 & 0.735061 & OUT \\
\hline$\sigma_{y}^{2}$ & 0.000609 & 0.000986 & 0.000032 & OUT \\
\hline$\sigma_{\pi}^{2}$ & 0.000056 & 0.000095 & 0.000029 & OUT \\
\hline$\sigma_{r}^{2}$ & 0.000072 & 0.000131 & 0.000067 & OUT \\
\hline
\end{tabular}

calibrated parameters and the test shows rejection. Tables 1 and 2 , show results before estimation, the VAR coefficients of the joint distribution's variables chosen using the calibrated parameters show the Wald statistic bootstrap distribution and where the Wald statistic data lies. I show the joint distribution's Mahalanobis Distance, ${ }^{10}$ normalized to a t-statistic as well as the Wald $p$ value. ${ }^{11}$

Tables 3 and 4 show results of indirect inference testing of the estimated model, using the simulated annealing algorithm. This means the algorithm is able to find the model parameters gets closer to the data. The auxiliary model used in the estimation, output-inflation-interest rate, fits the data. One can conclude, with respect to the summary of the result, that the model is not rejected by the data. One can see that the output and inflation variances are outside the $95 \%$ percentile but the data does not reject the model.

Table 5 shows the estimated structural parameters of the model. The value of the habit persistence parameter, 0.7, is consistent with the value reported by Boldrin et al.

10 The Mahalanobis Distance is the square root value of the Wald chi-squared distribution then into a normalised t-statistic by adjusting the mean and the size. The value is normalised by ensuring that the resulting t-statistic is 1.645 at the $95 \%$ point of the distribution, following Le et al. (2013).

11 Falls within $1 \%$ boundary. 
Table 3 Summary of VAR results

\begin{tabular}{llll}
\hline $\begin{array}{l}\text { Variables used in testing: output, } \\
\text { inflation and interest rate }\end{array}$ & Normalized T-statistic & Wald (\%) & $p$ value \\
\hline Dynamics & 0.7980 & 83.1 & 0.169 \\
Dynamics and volatility & 1.498 & 94 & 0.060 \\
Volatility & 2.1861 & 97.4 & 0.026 \\
\hline
\end{tabular}

Table 4 VAR results

\begin{tabular}{lrrrl}
\hline Categories & $95 \%$ lower & $95 \%$ upper & Actual & IN/OUT \\
\hline$A_{y}^{y}$ & 0.721125 & 0.955407 & 0.933917 & IN \\
$A_{y}^{\pi}$ & -0.159182 & 0.039341 & -0.054771 & IN \\
$A_{y}^{r}$ & -0.089259 & 0.083968 & -0.062042 & IN \\
$A_{\pi}^{y}$ & -0.059268 & 0.200526 & 0.107079 & IN \\
$A_{\pi}^{\pi}$ & 0.744558 & 0.933653 & 0.810838 & IN \\
$A_{\pi}^{r}$ & -0.167904 & 0.036061 & -0.093553 & IN \\
$A_{r}^{y}$ & -0.025819 & 0.273290 & 0.151025 & IN \\
$A_{r}^{\pi}$ & -0.079204 & 0.197448 & 0.190834 & IN \\
$A_{r}^{r}$ & 0.701350 & 0.924074 & 0.735061 & IN \\
$\sigma_{y}^{2}$ & 0.000034 & 0.000061 & 0.000032 & OUT \\
$\sigma_{\pi}^{2}$ & 0.000039 & 0.000078 & 0.000029 & OUT \\
$\sigma_{r}^{2}$ & 0.000059 & 0.000107 & 0.000067 & IN \\
\hline
\end{tabular}

(2001). They argued the ability of a standardized DSGE model accounts for the equity premium among other points. The Taylor rule coefficient of output and inflation, elasticity of demand for exports and imports are consistent with a lot of authors' estimations, e.g. Christiano et al. (2005), Smets and Wouters (2007) and Le et al. (2013). Table 6 shows the persistence ${ }^{12}$ and volatility ${ }^{13}$ of the shocks after estimation. With focus on group of shocks that are related to rest of the world that I refer to as foreign shocks (oil prices shock; gas prices shock; foreign interest rate shock; foreign demand shock and; world imports price shock), one can observe the presence of high persistence except in energy price shock even after estimation. This means current observed energy prices shocks depend on a larger contribution of the shock from the previous period. Again, the volatility of the foreign shocks is high compared to rest of the structural shocks in the model. Conversely, the productivity shock has low persistence and low volatility which is only bettered by the mark-up shock of prices after estimation.

\footnotetext{
12 Each shock persistence is given as the coefficient (rho), of that shock, generated from the data residual regressed on its lagged data (Wickens 1982).

13 The volatility is the standard error from the shock's innovation (Wickens 1982). This is also what is given to generate the impulse response functions of each shock using dynare.
} 
Table 5 Simulated annealing estimates of model parameters

\begin{tabular}{|c|c|c|c|c|}
\hline Parameter & Definition & Initial & Estimate & Change $(\%)$ \\
\hline$\theta_{y}$ & Taylor rule coefficient on output & 0.125 & 0.1291 & 3.3 \\
\hline$\varepsilon_{p}$ & Degree of indexation: non-energy sector & 0.5 & 0.4055 & -18.9 \\
\hline$\chi_{p}$ & $\begin{array}{l}\text { Probability of not being able to change price: } \\
\text { non-energy sector }\end{array}$ & 0.5 & 0.6474 & 29.5 \\
\hline$\varepsilon_{p m}$ & Degree of Indexation: importers & 0.5 & 0.5145 & 2.9 \\
\hline$\xi_{p m}$ & Probability of not able to change price: importers & 0.5 & 0.2109 & -57.8 \\
\hline$\eta_{x}$ & Elasticity of demand for exports & 1.5 & 2.4545 & 63.6 \\
\hline$\psi_{z}$ & Degree of persistence in export demand & 0.5 & 0.1844 & -63.1 \\
\hline$\psi_{h a b}$ & Degree of habit persistence in consumption & 0.5 & 0.6965 & 39.3 \\
\hline$\sigma_{c}$ & Intertemporal elasticity of substitution & 0.66 & 0.6681 & 1.2 \\
\hline$\varepsilon_{k}$ & $\begin{array}{l}\text { Degree of persistence in investment adjustment } \\
\text { costs }\end{array}$ & 0.5 & 0.9055 & 81.1 \\
\hline$\psi_{w}$ & Probability of being able to change wages & 0.5 & 0.3809 & -23.8 \\
\hline$\xi_{w}$ & Degree of wage indexation & 0.5 & 0.9678 & 93.6 \\
\hline$\sigma_{h}$ & Frisch elasticity of labour supply & 0.43 & 0.0149 & -96.5 \\
\hline$\theta_{r g}$ & Degree of Taylor-rule interest-rate smoothing & 0.5 & 0.4770 & -4.6 \\
\hline$\theta_{p d o t}$ & Taylor rule coefficient on inflation & 1.5 & 2.0637 & 37.6 \\
\hline$\chi_{z}$ & Scale of capital adjustment cost & 201 & 18.5928 & -90.7 \\
\hline$\psi_{w c}$ & Share of wage bill paid financed by borrowing & 0.5 & 0.0272 & -94.6 \\
\hline$\chi_{u}$ & Prob. not being able to change price: utility & 0.5 & 0.0886 & -82.3 \\
\hline$\chi_{p p}$ & Prob. not being able to change price: petrol & 0.5 & 0.6296 & 25.9 \\
\hline$\varepsilon_{u}$ & Degree of indexation: utilities sector & 0.5 & 0.4476 & -10.5 \\
\hline$\varepsilon_{p p}$ & Degree of indexation: petrol sector & 0.5 & 0.9363 & 87.3 \\
\hline$\phi_{z}$ & Inverse elasticity of capital utilisation costs & 0.56 & 0.8453 & 50.9 \\
\hline$\sigma_{w}$ & Elasticity of demand for differentiated labour & 3.8906 & 1.3617 & -65.0 \\
\hline
\end{tabular}

Table 6 Estimated parameters of structural shocks AR(1)

\begin{tabular}{lll}
\hline Shock $(j)$ & $\rho_{j}$ & $\sigma_{j}$ \\
\hline Productivity shock & 0.6453 & 0.0106 \\
Consumption preference shock & 0.8796 & 0.0153 \\
Government spending shock & 0.7811 & 0.0111 \\
Monetary policy shock & 0.8363 & 0.0106 \\
Capital adjustment cost shock & 0.4545 & 0.0284 \\
Price mark-up shock & 0.5695 & 0.0037 \\
Gas price shock & 0.8701 & 0.0744 \\
Foreign export price shock & 0.9415 & 0.0256 \\
Oil price shock & 0.7944 & 0.1265 \\
Foreign interest rate shock & 0.8348 & 0.0160 \\
Wage mark-up shock & 0.9381 & 0.0322 \\
Foreign demand shock & 0.9083 & 0.0559 \\
\hline
\end{tabular}



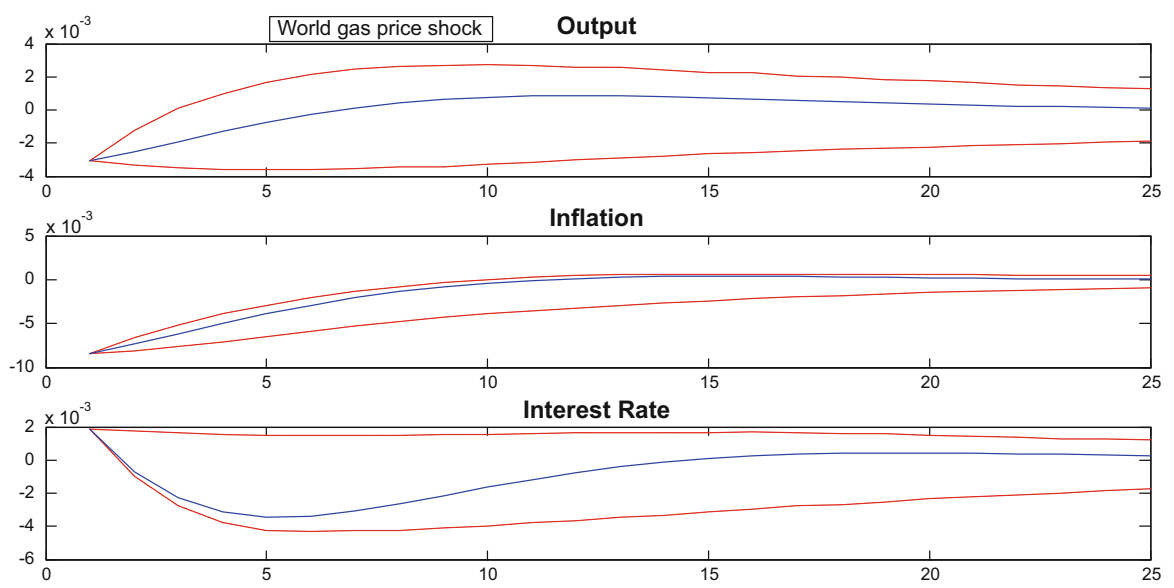

Fig. 3 VAR IRFs for a gas price shock
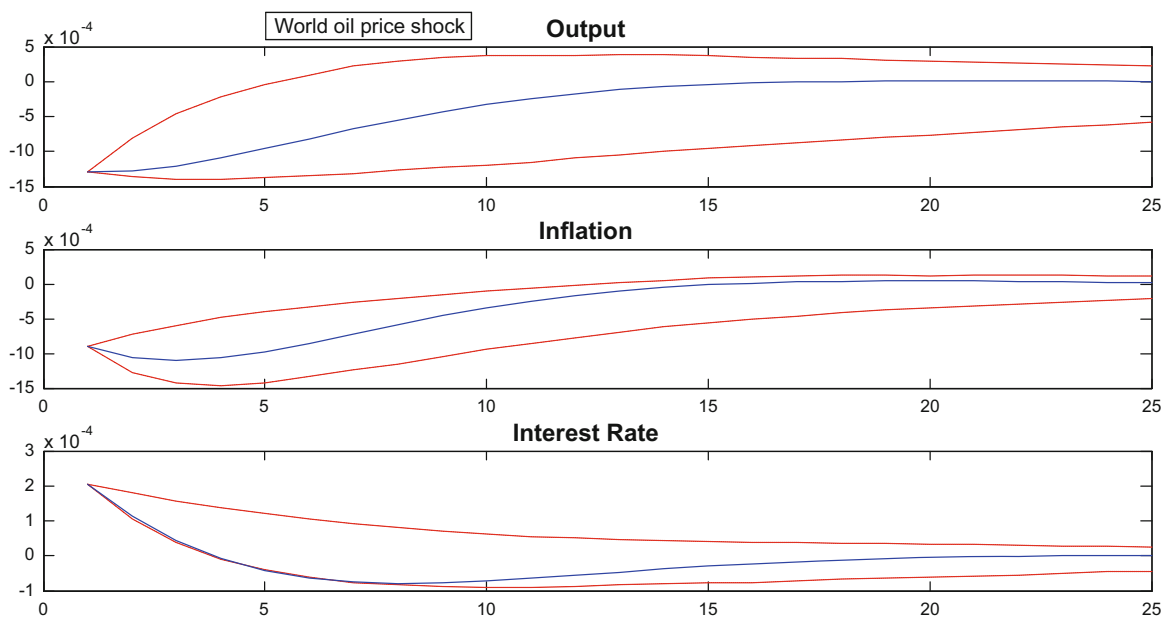

Fig. 4 VAR IRFs for an oil price shock

\subsection{Vector Autoregressive Model Impulse Response Functions (VAR-IRFs)}

The VAR-IRFs shows the fit of the calibrated model. Authors like Christiano et al. (2005) evaluated their model of the US exclusively on the fit to the structural shock IRFs. This follows Le et al. (2009), where the model estimation base on passing the Wald test using VAR(1). We collected the starting points of the VAR-IRFs using the 1000 bootstrapped coefficients. First, we ranked the coefficients, then collected the upper and lower 25 columns that makes the 5the starting point of the IRFs for each shock then simulated the model using dynare to derive the VAR-IRFs of each shock. The process generates 95responses that simply includes the data-based VAR responses to the structural shocks for the variables in the auxiliary model, output, inflation and interest rate. I show the VAR IRFs of the energy prices shocks and productivity shock. 

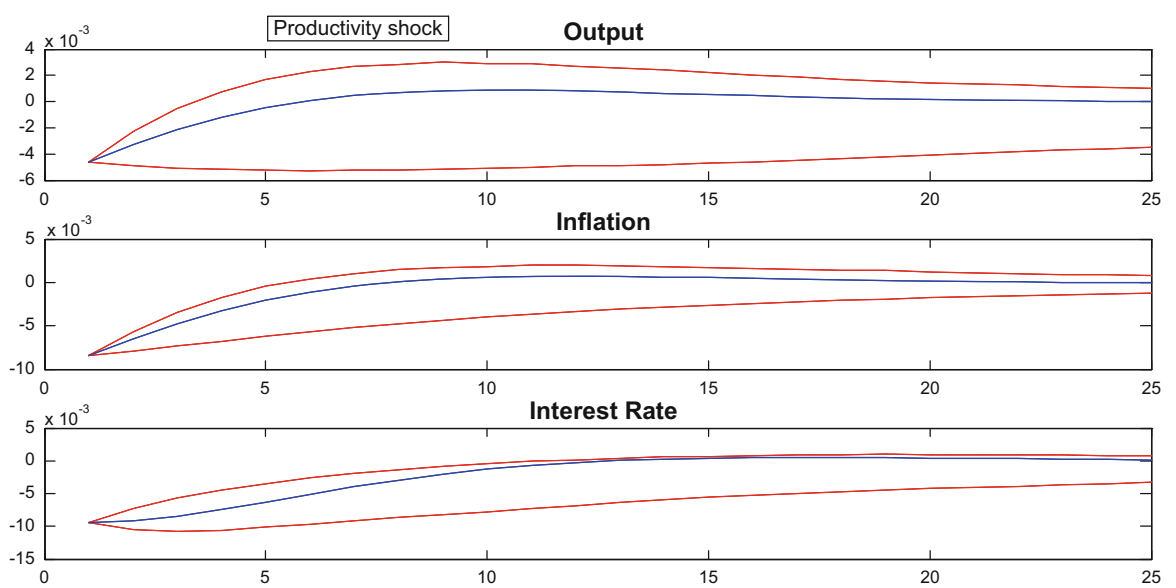

Fig. 5 VAR IRFs for a productivity price shock

The red lines indicate 95auxiliary model falls within the 95is within the upper or lower bounds, it means that the model fits data. The response is identified in a similar assumption of the real aggregate output, aggregate demand and real exchange rate evolve in this DSGE model. The behaviour of these endogenous variables displays the model fits the data and information of identification of the model using full set of VAR coefficients. In each figure, the $y$-axis refers to percentage change of a variable against steady state value in response to a shock while the $x$-axis refers to 'quarters' as the shocks are presumed to occur in the first quarter where I use matlab to generate the VAR-IRFs. The IRF figures and explanation are in "Appendix 3".

\subsection{A Stochastic Variance Decomposition}

Table 7 and 8 shows the significance of each shock in terms of how much each shock explains the variance in the endogenous variables. ${ }^{14}$ It is quite surprising that the productivity shock does not have effect on output. This is because the productivity shock affects non-energy gross output, ${ }^{15}$ with output (value-added) used as input. Hence, one can see productivity shock explains only $4 \%$ of its variability and just a little over $1 \%$ of the total gross output and output. Due to the feature of productivity shock, it explains most of the variables including investment at $0.5 \%$, employment at about $2 \%$ except marginal cost which it contributes almost $10 \%$ to its variability. The monetary policy shock dominates as it contributes $20 \%$ to gross output and $9 \%$

\footnotetext{
14 In this analysis, the shocks are classified as foreign or domestic. The domestic shocks are classified as productivity, monetary, domestic demand; which include consumption preference, capital adjustment cost and government spending [this is following Smets and Wouters (2007)], mark-up; includes price and wage mark-up. and finally the foreign shocks (world oil price, world gas price, foreign interest rate, foreign demand and world imports price) .

15 Value-added are used as inputs for gross output.
} 


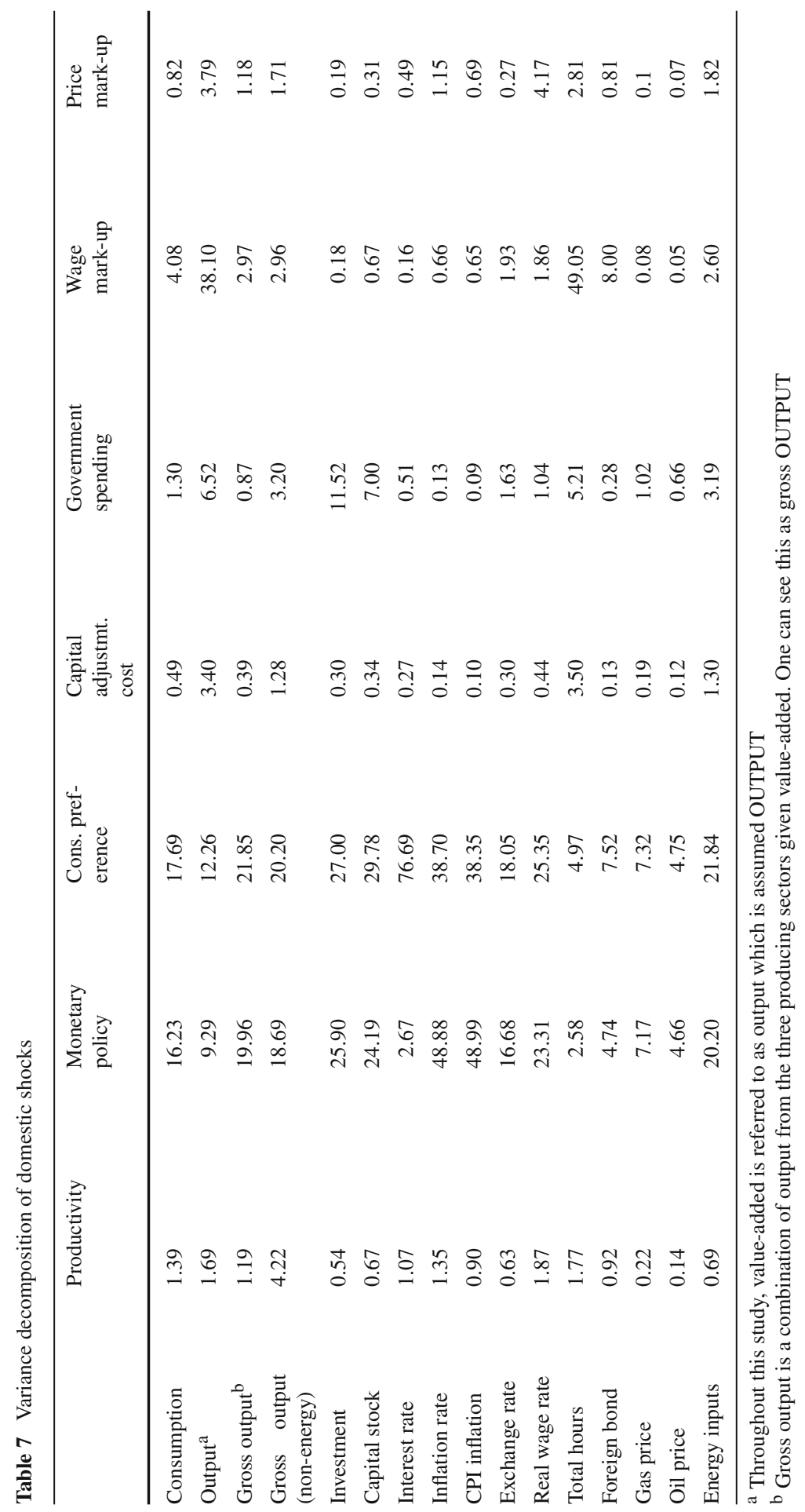


Table 8 Variance decomposition of foreign shocks

\begin{tabular}{lcccrc}
\hline & $\begin{array}{l}\text { Foreign } \\
\text { interest } \\
\text { rate }\end{array}$ & Gas price & Oil price & $\begin{array}{r}\text { Foreign } \\
\text { exports }\end{array}$ & $\begin{array}{r}\text { Foreign } \\
\text { demand }\end{array}$ \\
\hline Consumption & 16.50 & 0.49 & 0.08 & 20.64 & 20.28 \\
Output & 15.67 & 0.84 & 0.45 & 1.40 & 6.60 \\
Gross output & 14.13 & 1.92 & 0.63 & 17.32 & 17.61 \\
Gross output (non-energy) & 11.76 & 0.58 & 0.24 & 19.04 & 16.11 \\
Investment & 31.84 & 0.06 & 0.03 & 1.13 & 1.30 \\
Capital stock & 27.52 & 0.17 & 0.04 & 5.81 & 3.51 \\
Interest rate & 17.54 & 0.15 & 0.08 & 0.14 & 0.24 \\
Inflation rate & 7.59 & 0.18 & 0.90 & 0.16 & 0.18 \\
Consumer price inflation & 9.72 & 0.25 & 0.10 & 0.10 & 0.06 \\
Exchange rate & 32.67 & 0.10 & 0.04 & 1.90 & 25.80 \\
Real wage rate & 9.72 & 1.26 & 0.51 & 16.18 & 14.28 \\
Total hours & 12.01 & 0.64 & 0.32 & 5.89 & 11.24 \\
Foreign bond & 19.50 & 0.50 & 0.06 & 15.78 & 41.77 \\
Gas price & 59.97 & 2.01 & 0.02 & 13.01 & 8.89 \\
Oil price & 0.03 & 1.31 & 73.99 & 8.44 & 5.77 \\
Energy inputs & 12.48 & 2.68 & 0.53 & 15.50 & 17.17 \\
\hline & & & & & \\
\hline
\end{tabular}

of output. $16 \%$ of consumption is explained by this shock as it also contributes $41 \%$ to wage inflation and $49 \%$ to consumption inflation.

Domestic demand shock (a combination of preference shock, capital adjustment cost shock and government spending shock ${ }^{16}$ ) explains about $80 \%$ of the variance in interest rates. It also explains about $55 \%$ of the variations of capital stock and $53 \%$ of investment, $49 \%$ of inflation rates as well as $38 \%$ of consumption inflation. Demand shock contributes $20 \%$ to the variation, except exchange rate, and has effects on real wage rate as it contributes $25 \%$ to its variance. It also contributes 20 and $21 \%$ in explaining consumption and output, respectively. The mark-up shock (a combination of price and wage mark-up shock) explains about $42 \%$ of output, $51 \%$ of employment and $60 \%$ of the marginal rate of substitution (MRS).

However, it is the combined foreign shocks that explain $57 \%$ of output variation. These shocks explain that about $60 \%$ of the exchange rate variation is impacted by the foreign shocks with the foreign interest rate shock accounting for 32 and $46 \%$ of gross output of non-energy. The energy price shock that includes oil price and gas price shocks have little effect on the economic variables. Looking at the energy sector inflation, one can see the impact of the energy prices shock as it explains $57 \%$ of the petrol price inflation, $75 \%$ of the oil price and $36 \%$ of the utility price inflation.

16 Following Smets and Wouters (2007). 

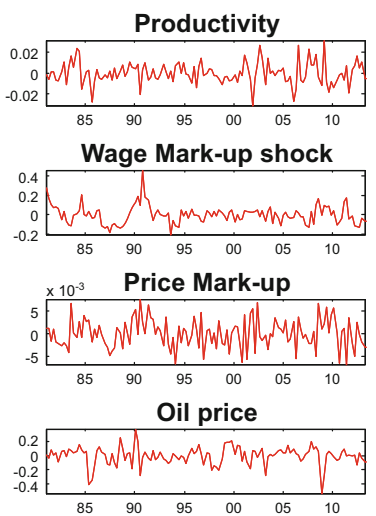

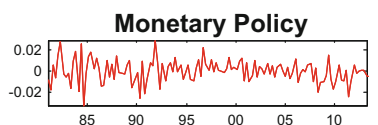

Consumption Preference


Domestic Demand

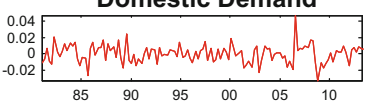

Capital adjustment cost



Foreign exports Price

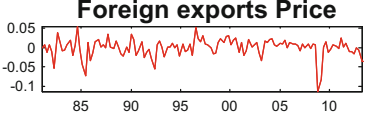

Foreign Demand

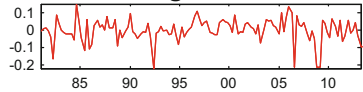

Fig. 6 Shocks' innovations

\subsection{Discussion: What the Model Says About Energy Price Shocks}

After 1980, observed energy prices show huge decrease, especially in crude oil prices (Hamilton 2003), until 1986 when prices begin to rise significantly. Figure 6 and shows the time series for the shocks in the model, which include the domestic as well as foreign shocks. As noted earlier, from the estimation results, one can see that the shocks to energy prices, wage mark-up and foreign demand have been highly volatile over this period. Conversely, monetary policy, productivity and consumption preference shocks have been less volatile. Observed data of the past financial crisis show that the world economies were hugely impacted by energy prices shocks and foreign demand shock. The foreign demand shock reflects what happened to world trade during the 2008 and the 2009 calendar year.

\subsubsection{Shock Decomposition During the Crisis Period}

The recent financial crisis of 2008-2009 was caused by an enormous decrease in market lending, that led to a drop in consumer confidence due to the crisis in the financial sector. It led to fall in foreign demand for home goods as a result of the global recession, government's austerity measures by governments that contributed to the initial fall in output among many others. Here, I decompose what happened during the crisis period as a result of the shocks, according to the model. By doing this, I show what determines the shocks that have been the main drivers of these variables. Here, I show the crisis period of output, non-energy gross output, inflation and interest rate. The crisis period was not caused by a rise in oil price but rather oil prices peaked as the recession was kicking in, and governments were taking austere measures to curb it. Matters were complicated as the rise in oil prices caused cost-push inflation that made central banks reluctant to reduce the interest rate. World oil prices peaked during this period which contributed to lower spending as a result of a reduction in discretionary income. Global oil prices peaked due to high demand from China and India even as Europe, and the US were in a recession. 




Fig. 7 Shock decomposition of output

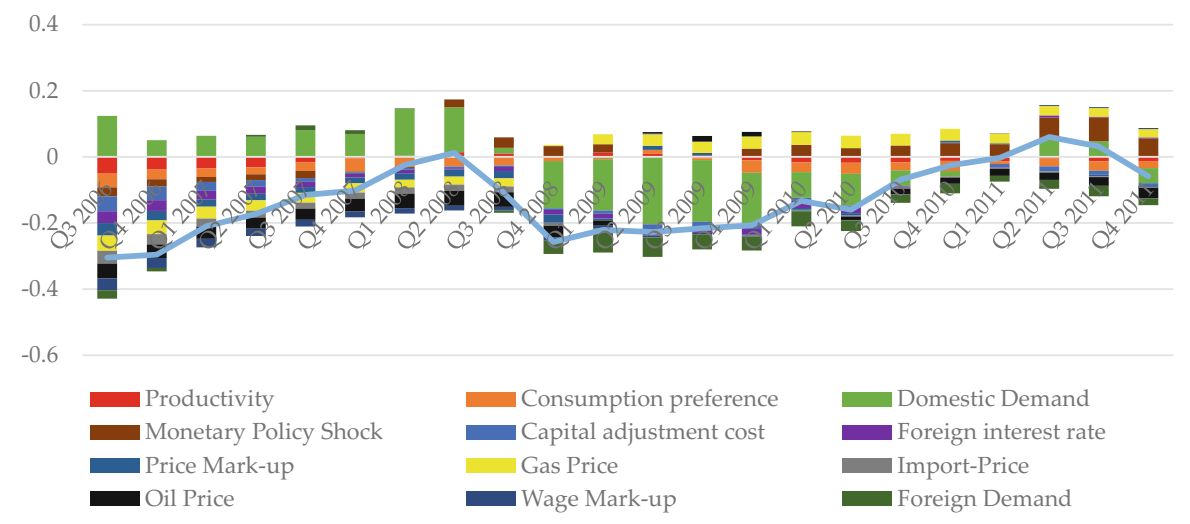

Fig. 8 Shock decomposition of non-energy gross output

For output, Fig. 7, exogenous government spending (light green) is most dominant, as expected, in the fall of output as also before the crisis where demand contributed to increasing output. Again, changes in oil prices which were similar to world gas prices are expected to be key in the fall of output during this period. From the output chart, one can see that the high oil prices (oil price shock is in black colour) of late 2008 noticeably contributed to the fall in output. Although gas prices (yellow) are high which shows energy prices were also pushing up on output towards the end of the period.

Looking at the non-energy gross output, in Fig. 8, domestic demand shock dominates while there is a foreign demand (purple) was non-existent due fall in exports as a result of the global recession. One can see how the oil price contributed to lower output, hence the financial crisis. This is because energy is part of the inputs of firm's production goods and because energy peaked over this period. As a result of a peak in energy prices, firms will have to reduce demand for energy and cut down production while household demand declines (both foreign and domestic demand shock). The fall in demand is a temporary shock because the study uses stationary data, that makes the 
0.2

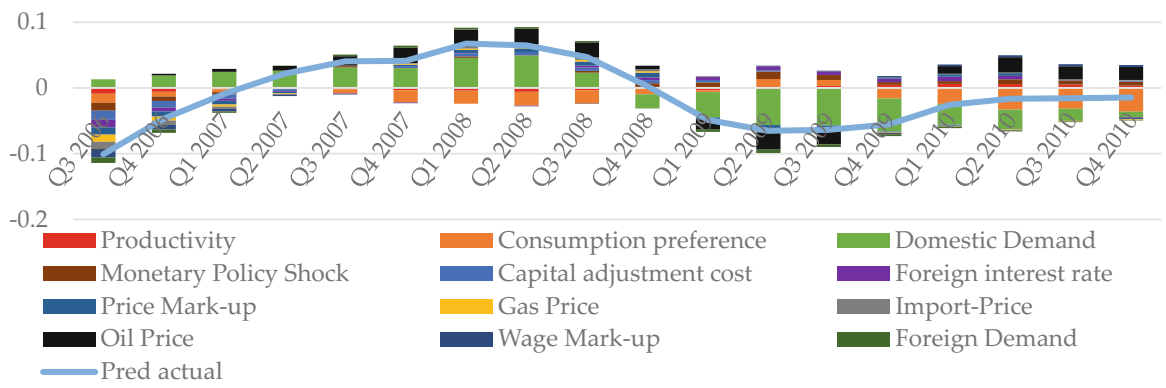

Fig. 9 Shock decomposition of real interest rate

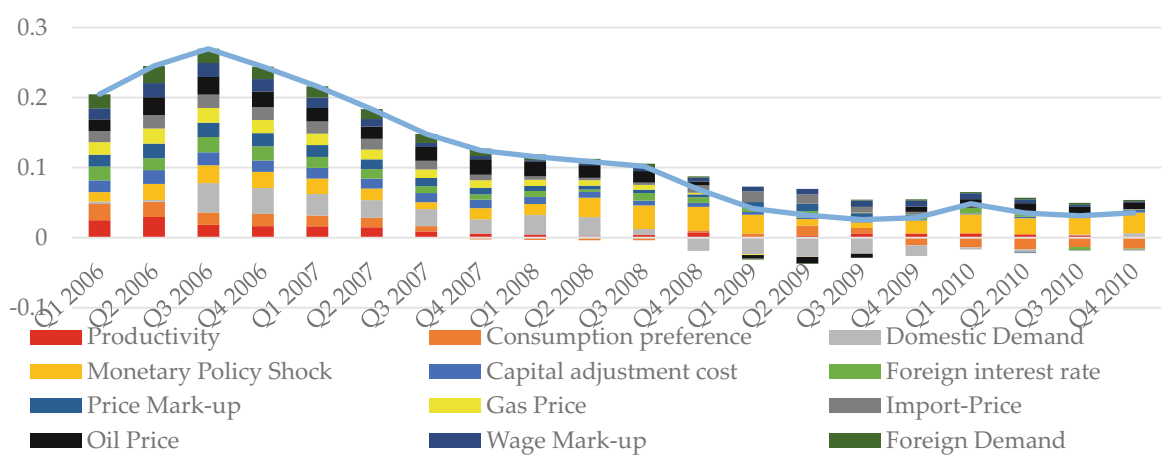

Fig. 10 Shock decomposition of Inflation rate

structural shocks to have no permanent effect on macroeconomic aggregates. Therefore, the UK government had to borrow to cover such losses. One can see the monetary shock was supporting output in during the crisis period due to interest rates cuts by higher than what would have been recommended by the Taylor rule in the model. Evidently, the 'systematic' monetary policy response is contributing to output coming from quantitative easing. These results are consistent with DSGE models theories. However, unlike Millard (2011) this study show energy prices shocks have significant effects on output and Gross output.

For interest rate, Fig. 9, shows that there is a domination by government exogenous spending shock. This comes from the effects the shock has on the output that pulls down real interest rate from 2008: Q3 as it falls steeply. Also the consumption preference shock that comes in as a result of lower consumer confidence as a result of financial instability and the credit crunch. World oil price shock is visible in 2009 as interest rates were at minimal, and the recession was impacting more.

Looking at inflation, Fig. 10, the shock decomposition suggests that the monetary policy shock was pushing down substantially on inflation from 2008: Q3 to 2010: Q4 with the domestic shock as well as energy prices also contributing. Contrary to this, positive foreign exports price shock, from 2008: Q4 to 2009: Q4, were contributing to pushing inflation up. The rise in oil prices and gas prices in 2008: Q1, and later in 2009: Q4, gas prices throughout 2008 put pressure on inflation to increase in 2008. 
Therefore, as oil and gas prices began to drop in 2009, they again moved to reduce inflation.

\section{Conclusion}

As the policymaker is only concerned about improving the state of the economy, I quantitatively apply a DSGE model to study the behaviour of macroeconomic aggregates, given the state of the world, in the UK. I use the indirect inference testing method of assessment that proves to be an efficient practical tool of evaluating a DSGE model that overcomes one of the major problems that are faced by DSGE models, that is identification, while estimating parameters. The VAR coefficients and Wald statistic possess the of identification information as identified. In matching the data, the shock processes play a key role as the foreign shocks (especially the energy prices shock) show high persistence. The shock decomposition, derived from the simulated model, is consistent with observed data and the literature by showing a NKPC model of inflation depends on lagged inflation, expected future inflation and the real marginal cost. By decomposing the changes in the variables caused by each of the structural shocks, I show that a fall in output during the financial crisis period 2008: Q1 to 2009: Q4 was driven by domestic demand shocks, accentuated by oil prices shocks and world demand shocks. The model shows that the effects of the stationary energy prices shock on output are only a temporary terms of trade shock as output only falls briefly, as the UK can borrow against such a temporary fall. The reason for having stationary shocks is because I use filtered data.

Meenagh et al. (2012) noted that filtering data may distort a DSGE model's dynamic properties in some unknown ways. This could be from the way that the HP-filter alters the lag dynamic structure or generating cycles where none exists. One of the reasons the model show low effects of productivity shocks. The forward-looking properties of the model are also transformed due to the filter being two-sided. As a result, there could be a serious defect in the DSGE model estimation. The study suggests a promising avenue for future research which is evaluating the model on non-stationary UK data. Several studies have shown that oil prices have proven to be non-stationary, and that requires the model to incorporate non-stationary exogenous variables of energy prices shock among others. All of the firms in this model are assumed to be energy efficient. An extension of this work would be to use unfiltered data and see the effects of energy prices shocks when treated as nonstationary shocks. Also, one can have a two-sector model of energy intensive and non-energy intensive firm, instead of three, with similar production functions in each firm. This can study the economic activities in the energy-intensive firms when energy prices change as well as the contribution of non-energy intensive firms when renewable is employed in such firms.

Open Access This article is distributed under the terms of the Creative Commons Attribution 4.0 International License (http://creativecommons.org/licenses/by/4.0/), which permits unrestricted use, distribution, and reproduction in any medium, provided you give appropriate credit to the original author(s) and the source, provide a link to the Creative Commons license, and indicate if changes were made. 


\section{Appendices}

\section{Appendix 1: The Log Linearized Model}

\section{The Household}

The model prescribes households to consume the three final goods as they supply differentiated labour to all three firms. Households are also assumed to own the capital stock and make decisions about capital accumulation and utilisation. Proceeds from the sale of oil and gas on world markets are distributed lump sum to consumers. Also, it is assumed that the capital utilisation decision depends on the price of energy, following Finn (2000). The hatted variables represent log deviation from trend.

The consumption Euler equation:

$$
\begin{aligned}
\hat{c}_{t}= & \frac{\psi_{h a b}\left(1-\sigma_{c}\right)}{1+\psi_{h a b}\left(1-\sigma_{c}\right)} \hat{c}_{t-1} \frac{1}{1+\psi_{h a b}\left(1-\sigma_{c}\right)} E_{t} \hat{c}_{t+1} \\
& \left(-\frac{\sigma_{c}}{1+\psi_{h a b}\left(1-\sigma_{c}\right)}\right)\left(\begin{array}{l}
i_{t}-E_{t} \pi_{c, t+1} \\
-\left(\frac{1}{\beta}-1\right)+\varepsilon_{b, t}
\end{array}\right) \\
\hat{w}_{k, t}= & \phi_{z} \hat{z}_{t}
\end{aligned}
$$

From Eq. (13) determines the choice of consumption by household while Eq. (14) shows the capital utilisation, $c$ represents the household's aggregate consumption, $E$ is the rational expectation term of expected variables, $\varepsilon_{b}$ is the consumption preference shock, $i$ is the nomianl rate of interest while $\pi_{c}$ is the consumer price index (CPI) inflation. The model explains real interest rate as $i_{t}-E_{t} \pi_{c, t+1} . w$ and $z$ denotes the efficient use of capital in production depends on the intensity of capital utilization. As for parameters, $\beta$ represent the discount factor, $\psi_{h a b}$ represents households' degree of habit formation in terms of consumption, while $\sigma_{c}$ represents the intertemporal substitution elasticity. Equation (15) represents the capital accumulation equation which shows lagged capital due to the assumption of capital adjustment costs:

$$
\begin{aligned}
& \left(i_{t}-E_{t} \pi_{c, t+1}-\left(\frac{1}{\beta}-1\right)+\varepsilon_{b}\right)=\left(\frac{\varepsilon_{k}}{1-\delta+\chi_{z}}+\left(1+\varepsilon_{k}\right)\right) \chi_{k} \hat{k}_{t-1} \\
& -\left(\frac{\left(1+\varepsilon_{k}\right)}{1-\delta+\chi_{z}}+1\right) \chi_{k} \hat{k}_{t}+\frac{\chi_{k}}{1-\delta+\chi_{z}} E_{t} \hat{k}_{t+1}-\chi_{k} \varepsilon_{k} \hat{k}_{t-2} \\
& +\frac{\chi_{k}}{1-\delta+\chi_{z}} E_{t} \hat{w}_{k, t+1}+\varepsilon_{i n v, t}
\end{aligned}
$$

Here, $k$ represents capital stock and $\varepsilon_{i n v}$ representing capital adjustment cost shock. $\chi_{k}$ represents the parameter that scales capital adjustment cost while $\chi_{z}$ scales the effect of capital and $\delta$ is the depreciation rate.

Aggregate consumption is composed of consumption of non-energy, petrol and utilities. 
Consumption of 'energy' will be given by:

$$
\hat{c}_{E, t}=\left(1-\psi_{P}\right) \hat{c}_{U, t}+\psi_{P} \hat{c}_{P, t}
$$

$c_{E}$ is consumption of energy, $c_{U}$ consumption of utility, $c_{P}$ is the consumption of petrol with the parameter $\psi_{P}$ as the share of petrol in energy consumption.

Hence, aggregate consumption is derived by , $c_{n}$ consumption of non-energy good, $c_{e}$ the consumption of energy goods with the parameter $\psi_{e}$ as the share of energy in consumption:

$$
\hat{c}_{t}=\left(1-\psi_{e}\right) \hat{c}_{n, t}+\psi_{e} \hat{c}_{e, t}
$$

Relative prices are given by $P_{U}$ price of utility and $P_{P}$ price of petrol which depends on consumption from different sectors and firms:

$$
\hat{P}_{U, t}=-\frac{1}{\sigma_{e}} \hat{c}_{n, t}+\left(\frac{1}{\sigma_{e}}-\frac{1}{\sigma_{p}}\right) \hat{c}_{E, t}+\frac{1}{\sigma_{p}} \hat{c}_{U, t}
$$

and

$$
\hat{P}_{U, t}-\hat{P}_{P, t}=-\frac{1}{\sigma_{p}} \hat{c}_{U, t}+\frac{1}{\sigma_{p}} \hat{c}_{P, t}
$$

The parameters, $\sigma_{e}$ and $\sigma_{p}$, represent elasticity of substitution between non-energy and energy in consumption and elasticity of substitution between petrol and utilities in energy consumption.

The households assume to have an option of holding either foreign or domestic bonds, as trade in foreign bonds, $b_{f}$, incurs quadratic costs. This results in the UIP condition:

$$
E_{t} \hat{s}_{t+1}-\hat{s}_{t}=-\left(i_{t}-\left(\frac{1}{\beta}-1\right)\right)+\chi_{b f} b_{f, t}+\varepsilon_{r f, t}
$$

$s$ represents the foreign exchange, $\varepsilon_{r f}$ is the foreign interest rate shock while $\chi_{b f}$ represents adjustment cost portfolio.

The model assumes household to be a monopoly supplier of differentiated labor. Therefore, households will set real wage, $w$, as a mark-up over the marginal rate of substitution between consumption and leisure that is the percentage deviation denoted by mrs. This is subject to nominal wage stickiness and partial indexation of wages to inflation. Hence, wage inflation, $\dot{W}$, is given as:

$$
\begin{aligned}
\dot{W}_{t}= & \frac{\xi_{w}}{1+\beta \xi_{w}} \dot{W}_{t-1}+\frac{\beta}{1+\beta \xi_{w}} E_{t} \dot{W}_{t+1} \\
& -\left(\frac{\psi_{w}\left(1-\beta\left(1-\psi_{w}\right)\right)}{\left(1+\frac{\sigma_{w}}{\sigma_{h}}\right)\left(1-\psi_{w}\right)\left(1+\beta \xi_{w}\right)}\right)\left(\hat{w}_{t}-m r s_{t}\right)+\varepsilon_{w, t}
\end{aligned}
$$


where

$$
m r s=\frac{1}{\sigma_{h}} \hat{h}_{t}+\frac{1}{\sigma_{c}}\left(\hat{c}_{t}+\psi_{h a b}\left(\sigma_{c}-1\right) \hat{c}_{t-1}\right)
$$

and real wages

$$
\hat{w}_{t}=\dot{W}_{t}+\hat{w}_{t-1}-\pi_{c, t}
$$

$h$ represents the hours work in the economy and $\varepsilon_{w}$ is the wage mark-up shock. In terms of parameters, $\xi_{w} \psi_{w} \sigma_{h}$, represents degree of wage indexation, probability of being able to change wages and Frisch elasticity of labour supply, respectively.

\section{The Firm}

Production is assumed to be divided into three sectors of non-energy producing firm and energy producing firm:

Non-energy producing firm

$$
\hat{q}_{t}=\left(1-\alpha_{q}\right) \hat{B}_{t}+\alpha_{q} \hat{e}_{t}+\varepsilon_{a, t}
$$

where

$$
\hat{B}_{t}=\left(1-\alpha_{B}\right) \hat{V}_{n, t}+\alpha_{B} \hat{M}_{n, t}
$$

and

$$
\hat{e}_{t}=\hat{I}_{p, t}=\hat{I}_{u, t}
$$

where $q$ denotes gross output of non-energy, and $\varepsilon_{a}$ represents the productivity shock. $B$ denotes bundle of value-added, $V_{n}$, and intermediate imported goods, $M_{n} ; e$ denotes energy input in this sector, which will be given by (26). The parameters $\alpha_{q}$ and $\alpha_{B}$ are the Cost share of energy in non-energy output and cost share of imports in 'bundle', respectively.

The cost minimization shows the demand curve for:

$$
\begin{array}{ll}
\text { Value-added } & \hat{V}_{n, t}=\hat{\mu}_{t}-\hat{p}_{v c, t}+\frac{1}{\sigma_{q}} \hat{q}_{t}+\frac{\sigma_{q}-1}{\sigma_{q}} \hat{B}_{t}+\frac{\sigma_{q}-1}{\sigma_{q}} \varepsilon_{a, t} \\
\text { imports } & \hat{M}_{n, t}=\hat{\mu}_{t}-\hat{p}_{m, t}+\frac{1}{\sigma_{q}} \hat{q}_{t}+\frac{\sigma_{q}-1}{\sigma_{q}} \hat{B}_{t}+\frac{\sigma_{q}-1}{\sigma_{q}} \varepsilon_{a, t} \\
\text { energy } & \hat{e}_{t}=\sigma_{q} \hat{\mu}_{t}+\hat{q}_{t}-\sigma_{q}\left(\psi_{n} \hat{p}_{p, t}+\left(1-\psi_{n}\right) \hat{p}_{U}\right)+\left(\sigma_{q}-1\right) \varepsilon_{a, t}
\end{array}
$$

where $\mu$ is real marginal cost and $p_{v c}$ is the 'competitive' price of value-added (the marginal cost of producing it). $\psi_{n}$ is the cost share of petrol in energy output and $\sigma_{q}$ is elasticity of substitution between energy and everything else in non-energy production. 
Firms in the non-energy sector are also subject to nominal rigidities in their pricesetting. In particular, each period they are only allowed to set their price optimally with a probability of $11-\chi_{p}$, with $\chi_{p}$ being the Probability of not being able to change price in the non-energy sector. If they cannot change their price optimally, they partially index their price to lagged inflation.

The resulting NKPC is:

$$
\pi_{t}=\frac{\beta}{\left(1+\beta \varepsilon_{p}\right)} E_{t} \pi_{t+1}+\frac{\varepsilon_{p}}{\left(1+\beta \varepsilon_{p}\right)} \pi_{t-1}+\frac{\left(1-\chi_{p}\right)\left(1-\beta \chi_{p}\right)}{\left(1+\beta \varepsilon_{p}\right) \chi_{p}} \hat{\mu}_{t}+\varepsilon_{\mu, t}
$$

$\pi_{t}$ represents inflation rate and $\varepsilon_{\mu}$ is the price mark-up shock. $\varepsilon_{p}$ is the degree of indexation in the non-energy sector.

\section{Value-Added}

The producers of value-added use capital to produce value-added, V: The equation is a CES Cobb-Douglas production function for value-added output.

$$
\hat{V}_{t}=\left(1-\alpha_{v}\right) \hat{h}_{t}+\alpha_{v}\left(\hat{k}_{t-1}+z_{t}\right)
$$

The parameter $\alpha_{v}$ is the elasticity of substitution between labour and capital in valueadded production. It is assumed that value-added producers need to borrow the money to finance a proportion, $\omega_{w c}$ of their wage bill. This assumption has been used by many others, such as Fuerst (1992) and Christiano and Eichenbaum (1992, 1995), and implies a 'cost channel' of monetary transmission.

Cost minimization by value-added producers implies the following demand curves for capital and labor:

$$
\begin{gathered}
\hat{h}_{t}=\hat{V}_{t}+\sigma_{V}\left(\hat{p}_{v c, t}-\hat{w}_{t}-\omega_{w c}\left(i_{t}-\left(\frac{1}{\beta}-1\right)+\varepsilon_{b, t}\right)\right) \\
\hat{k}_{t-1}+\hat{z}_{t}=\hat{V}_{t}+\sigma_{V}\left(\hat{p}_{v c, t}-\hat{w}_{k, t}\right)
\end{gathered}
$$

$\sigma_{V}$ represents the elasticity of substitution between labour and capital in value-added production

\section{Petrol Producers}

Petrol, $\hat{q}_{p}$ is produced using inputs of crude oil, $\hat{\mathrm{I}}_{\mathrm{o}}$ and value-added $\hat{\mathrm{V}}_{\mathrm{p}}$. A simple Leontieff production function is assumed because, in reality, increasing the number of workers to a given amount of crude oil cannot increase the amount of oil output, hence: 


$$
\begin{aligned}
\hat{q}_{p, t}= & \hat{I}_{o, t}=\hat{V}_{p, t} \\
\pi_{p b, t}= & \frac{\beta}{\left(1+\beta \varepsilon_{p p}\right)} E_{t} \pi_{p b, t+1}+\frac{\varepsilon}{\left(1+\beta \varepsilon_{p p}\right)} \pi_{p b, t-1} \\
& +\frac{\left(1-\chi_{p}\right)\left(1-\beta \chi_{p}\right)}{\left(1+\beta \varepsilon_{p p}\right) \chi_{p p}} \hat{\mu}_{p t} \\
\hat{\mu}_{p, t}= & \psi_{q p} \hat{p}_{v c, t}+\left(1-\psi_{q p}\right) \hat{p}_{o, t}-\hat{p}_{p b, t} \\
\pi_{p b, t}= & \pi_{t}+\hat{p}_{p b, t}-\hat{p}_{p b, t-1}
\end{aligned}
$$

The sector is subject to nominal rigidities when setting their prices which result in a NKPC (35). $\pi_{p b}$ is inflation on basic prices of petrol and $\hat{\mu}_{p}$ is the marginal cost on petrol. In the real marginal cost sector (35) $P_{O}$ is price of oil and $P_{p b}$ is the pre-duty of petrol price. In terms of parameters, $\varepsilon_{p p}$ is the degree of indexation in the petrol sector, $\chi_{p}$ is the probability of not being able to change price of petrol and $\psi_{q p}$ is the cost share of value-added in petrol output.

\section{Utilities Producers}

The utilities sector is similar to the petrol sector. It follows a Leontieff production function and all the basic assumptions stated above because, in reality, increasing the number of workers to a given amount of natural gas cannot increase the amount of gas and electricity produced $\hat{q}_{u}$, hence:

$$
\begin{aligned}
\hat{q}_{u, t}= & \hat{I}_{g, t}=\hat{V}_{u, t} \\
\pi_{u, t}= & \frac{\beta}{\left(1+\beta \varepsilon_{u}\right)} E_{t} \pi_{u, t+1}+\frac{\varepsilon}{\left(1+\beta \varepsilon_{u}\right)} \pi_{u, t-1} \\
& +\frac{\left(1-\chi_{p}\right)\left(1-\beta \chi_{u}\right)}{\left(1+\beta \varepsilon_{u}\right) \chi_{u}} \hat{\mu}_{u, t} \\
\hat{\mu}_{u, t}= & \psi_{u} \hat{p}_{v c, t}+\left(1-\psi_{u}\right) \hat{p}_{g, t}-\hat{p}_{u, t} \\
\pi_{u, t}= & \pi_{t}+\hat{p}_{u, t}-\hat{p}_{u, t-1}
\end{aligned}
$$

Utilities $\hat{q}_{u}$ is produced using inputs of natural gas, $\hat{\mathrm{I}}_{\mathrm{g}}$ and value-added $\hat{\mathrm{V}}_{g}$. The sector is subject to nominal rigidities when setting their prices which result in a NKPC (39). $\pi_{u}$ is inflation on utilities and $\hat{\mu}_{u}$ is the marginal cost on utilties. In the real marginal cost sector (40) $P_{g}$ is price of gas and $P_{u}$ is the price of utilities. In terms of parameters, $\varepsilon_{u}$ is the degree of indexation in the utilities sector, $\chi_{u}$ is the probability of not being able to change price of utilities and $\psi_{u}$ is the cost share of value-added in utilities output.

\section{Monetary and Fiscal Policy}

The monetary policy of the economy is assumed to follow a Taylor rule: 


$$
i_{t}-\left(\frac{1}{\beta}-1\right)=\theta_{r g}\left(i_{t-1}-\left(\frac{1}{\beta}-1\right)\right)+\left(1-\theta_{r g}\right)\left(\theta_{p d o t} \pi_{c, t}+\theta_{y} \hat{V}_{t}\right)+\varepsilon_{i, t}
$$

where the central bank responds to inflation target deviations and value-added. $\varepsilon_{i}$ is the monetary policy shock. The parameters $\theta_{r g}, \theta_{p d o t}$ and $\theta_{y}$ represents the degree of Taylor rule interest-rate smoothing, Taylor rule coefficient on inflation and Taylor rule coefficient on output, respectively.

The government's budget constraint is:

$$
G_{t}=\psi_{d} p_{p, t} q_{p, t}+T_{t}
$$

where the fiscal authority $(G)$ balances its budget using lump-sum taxes on consumers $(T)$. However, the unanticipated government spending comes from the domestic demand shock.

\section{Foreign Sector}

$$
\begin{array}{ll}
\text { World oil prices } & \hat{p}_{o, t}=\varepsilon_{p_{o}, t}-\hat{s}_{t} \\
\text { World gas prices } & \hat{p}_{g, t}=\varepsilon_{p_{g}, t}-\hat{s}_{t}
\end{array}
$$

where $\varepsilon_{p_{o}}$ and $\varepsilon_{g}$ represents the shocks to oil prices and gas prices, respectively. A combination of these two shock gives energy prices shock.

\section{Imports}

The imports prices in the economy is assumed to adjust purchasing power parity by taking a one period lag. The imports prices results from the NKPC:

$$
\begin{aligned}
\pi_{m, t}= & \frac{\varepsilon_{p m}}{\left(1+\beta \varepsilon_{p m}\right)} \pi_{m, t-1}+\frac{\beta}{\left(1+\beta \varepsilon_{p m}\right)} E_{t} \pi_{m, t+1} \\
& +\frac{\left(1-\xi_{p m}\right)\left(1-\beta \xi_{p m}\right)}{\left(1+\beta \varepsilon_{p m}\right) \xi_{p m}}\left(\varepsilon_{p_{m f}, t}-\hat{s}_{t}-\hat{p}_{m t}\right) \\
\pi_{m, t}= & \pi_{t}+\hat{p}_{m, t}-\hat{p}_{m, t-1}
\end{aligned}
$$

where $\pi_{m}$ is imports price inflation, $p_{m}$ is the imports price, and $\varepsilon_{p m} f$ is the imports price shock. $\varepsilon_{p m}$ is the degree of indexation for importers and $\xi_{p m}$ is the importers probability of not being able to change the price.

Exports

$$
\hat{x}_{n, t}=\psi_{z} \hat{x}_{n, t-1}\left(1-\psi_{z}\right)\left(\varepsilon_{y f, t}-\eta_{x} \hat{s}_{t}\right)
$$

The world demand is given above with $\hat{x}_{n}$ as exports of non-energy goods and $\varepsilon_{y f}$ representing the world demand shock. $\psi_{z}$ is the degree of persistence in export demand. 


\section{Market Clearing Conditions}

Equation (56) is the aggregate demand derivation where $\varepsilon_{g}$ represent the governments unanticipated shock, domestic demand shock. The market clearing conditions includes the simple aggregation of variables as well as the current account of the UK economy, in Eq. (57). Change in foreign bonds depends on net exports of energy, that is exports of crude oil $\hat{X}_{o}$ and exports of natural gas $\hat{X}_{g}$ less net imports of intermediate goods.

$$
\begin{aligned}
\hat{p}_{c, t}+\hat{c}_{t}= & \frac{c_{n}}{p_{c} c} \hat{c}_{n, t}+\frac{p_{u} c_{u}}{p_{c} c} \hat{p}_{U, t}+\hat{c}_{U, t}+\left(1-\frac{c_{n}}{p_{c} c}-\frac{p_{u} c_{u}}{p_{c} c}\right)\left(\hat{p}_{p, t}+\hat{c}_{p, t}\right) \\
\pi_{c, t}= & \frac{c_{n}}{p_{c} c} \hat{\pi}_{t}+\frac{p_{u} c_{u}}{p_{c} c} \pi_{u, t}+\left(1-\frac{c_{n}}{p_{c} c} \frac{p_{u} c_{u}}{p_{c} c}\right) \pi_{p b, t} \\
V_{t}= & \frac{V_{n}}{V_{t}} \hat{V}_{n, t}+\frac{V_{u}}{V_{t}} \hat{V}_{u, t}+\left(1+\frac{V_{n}}{V_{t}}-\frac{V_{u}}{V_{t}}\right) \hat{V}_{p, t} \\
\hat{q}_{p, t}= & \frac{c_{p}}{q_{p}} \hat{c}_{p, t}+\left(1-\frac{c_{p}}{q_{p}}\right) \hat{I}_{p, t} \\
\hat{I}_{O, t}= & -\frac{X_{o}}{I_{o}} \hat{X}_{O, t} \\
\hat{I}_{G, t}= & -\frac{X_{g}}{I_{g}} \hat{X}_{G, t} \\
\hat{q}_{u, t}= & \frac{c_{U}}{q_{U}} \hat{c}_{U, t}+\left(1-\frac{c_{U}}{q_{U}}\right) \hat{I}_{U, t} \\
\hat{q}_{t}= & \frac{c_{n}}{q} \hat{c}_{n, t}+\frac{k}{q} \hat{k}_{t}-\frac{(1-\delta) k}{q} \hat{k}_{t-1}+\frac{\chi_{z} k}{q} \hat{z}_{t}+\frac{x_{n}}{q} \hat{x}_{n, t}+\varepsilon_{g, t} \\
b_{f, t}= & \frac{1}{\beta} b_{f, t-1}+\frac{x_{n}}{q} \hat{x}_{n, t}+\frac{X_{g}}{q}\left(\hat{p}_{g, t}+\hat{X}_{g, t}\right) \\
& +\frac{X_{o}}{q}\left(\hat{p}_{o, t}+\hat{X}_{o, t}\right)-\frac{M_{n}}{q}\left(\hat{p}_{m, t}+\hat{M}_{n, t}\right)
\end{aligned}
$$

In terms of parameters, these are average ratios of derived aggregate variables in the economy. $\frac{c_{n}}{p_{c} c}$ is the share of non-energy consumption in total consumption, $\frac{p_{u} c_{u}}{p_{c} c}$ is the share of utility consumption in total consumption, $\frac{V_{n}}{V}$ is the share of value-added used as input in non-energy goods, $\frac{V_{u}}{V}$ is the share of value-added used as input in utilities, $\frac{c_{p}}{q_{p}}$ is the share of petrol output going to consumption, $\frac{c_{u}}{q_{u}}$ is the share of utilities output going to consumption, $\frac{X_{o}}{I_{o}}$ is the ratio of oil exports to oil inputs, $\frac{X_{g}}{I_{g}}$ is the ratio of gas exports to gas inputs, $\frac{c_{n}}{q}$ is the share of private consumption in non-energy output, $k / q$ is the ratio of capital to non-energy gross output, $\frac{x_{n}}{q}$ is the share of exports in nonenergy gross output, $\frac{M_{n}}{q}$ is the ratio of imports of non-energy goods to gross output of 
non-energy goods, $\frac{X_{O}}{q}$ is the ratio of oil exports to gross output of non-energy goods, $\frac{X_{g}}{q}$ is the ratio of gas exports to gross output of non-energy goods

\section{The Exogenous Shock Processes}

Shock processes follow autoregressive process of $\operatorname{AR}(1)$ where $\rho$ is the persistence and $\eta$ is the volatility.

$$
\begin{aligned}
\varepsilon_{a, t} & =\rho_{a} \varepsilon_{a, t-1}+\eta_{a, t} \\
\varepsilon_{b, t} & =\rho_{b} \varepsilon_{b, t-1}+\eta_{b, t} \\
\varepsilon_{g, t} & =\rho_{g} \varepsilon_{g, t-1}+\eta_{g, t} \\
\varepsilon_{i, t} & =\rho_{i} \varepsilon_{i, t-1}+\eta_{i, t} \\
\varepsilon_{\mu, t} & =\rho_{\mu} \varepsilon_{\mu, t-1}+\eta_{\mu, t} \\
\varepsilon_{i n v, t} & =\rho_{i n v} \varepsilon_{i n v, t-1}+\eta_{i n v, t} \\
\varepsilon_{w, t} & =\rho_{w} \varepsilon_{w, t-1}+\eta_{w, t} \\
\varepsilon_{y f, t} & =\rho_{y f} \varepsilon_{y f, t-1}+\eta_{y f, t} \\
\varepsilon_{p m f, t} & =\rho_{p m f} \varepsilon_{p m f, t-1}+\eta_{p m f, t} \\
\varepsilon_{p o, t} & =\rho_{p o} \varepsilon_{p o, t-1}+\eta_{p o, t} \\
\varepsilon_{p g, t} & =\rho_{p g} \varepsilon_{p g, t-1}+\eta_{p g, t} \\
\varepsilon_{r f, t} & =\rho_{r f} \varepsilon_{r f, t-1}+\eta_{r f, t}
\end{aligned}
$$

where $\eta^{\prime} s$ are all assumed to be i.i.d. normal processes.

Following the log-linearized model, there are 48 endogenous variables and twelve exogenous shocks have been added to the model which follow AR(1) process. These shocks are assumed to be temporary shocks in the economy. I divided the shocks into two: domestic shocks and foreign shocks. Domestic shocks include: productivity, monetary, consumption preference, capital adjustment cost, government exogenous spending, wage mark-up and price mark-up. While the foreign shocks are: foreign real interest rate, foreign demand, foreign exports price as well as oil price and gas price shocks.

\section{Appendix 2: Data}

In this section the data sources and construction are presented. The data for endogenous variables and exogenous forcing processes covers the period from 1981 Q1 to 2013 Q1. This period takes in the great moderation era of the UK and includes the 2008 financial crisis. Twenty-six variables were used in total for the estimation, with all variables being expressed in real terms. All variables are per capita and this is calculated by dividing through a UK working-age population, before taking natural logs and then detrended using the Hodrick-Prescott (HP) filter setting - the smoothing parameter $\lambda=1600$ except where the spatial econometrics toolbox has been used to detrend interest rate, inflation rate and, capital rental rate.

The ONS quarterly series (UKMGSL.Q) has been used when considering population. To calculate the aggregate consumption, the methodology of Harrison and Oomen 
(2010) was used, where the final consumption expenditure of households and NPISHs (ABJR.Q + HAYO.Q) has been used (ZAVO08) when considering consumption of energy. The consumption deflator is derived as (ABJQ.Q + HAYE.Q)/(ABJM.Q + HAYO.Q). For output I have used GVA at basic prices (ABMM.Q) and the output gap (XOGAP.R) has been used as a proxy for marginal cost. The interest rate used is the three-month Treasury bill rate series from Bank of England (BoE) database (IUQAAJNB). For total hours of employment, I have used the ONS series of (YBUS.Q). To calculate real wages, the UK wages (XPEWF.B) from ONS series have been divided by the total hours worked (YBUS.Q) and then divided through by the consumption deflator. Wage inflation is represented by wages and salaries YOY changes.

Inflation is CPI year-on-year, YOY henceforth, (XCPI.YR). The inflation on consumption is final consumption expenditure YOY (UKES\&NMZR). For nonenergy gross output, the data of Bank of England similar to Millard (2011) is used, the volume of the final output of the private non-oil and gas extraction sector (QNOCP.Q/PYNODEF.Q). For exchange rate, the Quarterly Average Effective exchange rate index XUQABK67 from BoE is used. Capital stock is constructed using gross fixed capital formation. The foreign bonds are represented by (UKNIJJ10). For the capital rental rate, the official bank rate (IUQABEDR) from BoE is used, while the capital utilization rate is represented by (XCAPU.R). The energy input data is a combination of gas sale to energy generators, gas sale to refinery, gas sale to iron and steel industry and finally gas sale to other sectors (SGASOIF + SGASISF + SGASPWF + RUFUELF). This is achieved without double counting.

For world data I have used the series of world imports prices (Q76.X.F) and followed the BEQM described in Harrison et al. (2005) to construct intermediate imports while I used the UK total imports price YOY as imports inflation (KH3K. R). Non-energy exports are data on trade in goods, less oil and eratics (UKBPBLQ). Finally, for oil and gas prices the world prices of each (WDXWPOB.A and WDXGASJ.A) were collected and then converted to pounds using the exchange rate series of US Dollar to British Pound (UKAUSSQ).

The estimated ${ }^{17}$ persistence and volatility of the shocks, following AR(1) process are:

$$
\begin{aligned}
\varepsilon_{a, t} & =0.6453 \varepsilon_{a, t-1}+\eta_{a, t}, \sigma_{a, t}=0.0106 \\
\varepsilon_{b, t} & =0.8809 \varepsilon_{b, t-1}+\eta_{b, t}, \sigma_{b, t}=0.0150 \\
\varepsilon_{g, t} & =0.7811 \varepsilon_{g, t-1}+\eta_{g, t}, \sigma_{g, t}=0.0111 \\
\varepsilon_{i, t} & =0.7631 \varepsilon_{i, t-1}+\eta_{i, t}, \sigma_{i, t}=0.0097 \\
\varepsilon_{\mu, t} & =0.3473 \varepsilon_{\mu, t-1}+\eta_{\mu, t}, \sigma_{\mu, t}=0.2021 \\
\varepsilon_{i n v, t} & =0.6542 \varepsilon_{i n v, t-1}+\eta_{i n v, t}, \sigma_{i n v, t}=0.0041 \\
\varepsilon_{p g, t} & =0.8701 \varepsilon_{p g, t-1}+\eta_{p g, t}, \sigma_{p g, t}=0.0744 \\
\varepsilon_{p m f, t} & =0.8755 \varepsilon_{p m f, t-1}+\eta_{p m f, t}, \sigma_{p m f, t}=0.0382
\end{aligned}
$$

17 Details of the estimation is provided in the Sect. 3. 


$$
\begin{aligned}
\varepsilon_{p o, t} & =0.7944 \varepsilon_{p o, t-1}+\eta_{p o, t}, \sigma_{p o, t}=0.1265 \\
\varepsilon_{r f, t} & =0.8369 \varepsilon_{r f, t-1}+\eta_{r f, t}, \sigma_{r f, t}=0.0155 \\
\varepsilon_{w, t} & =0.2891 \varepsilon_{w, t-1}+\eta_{w, t}, \sigma_{w, t}=0.0042 \\
\varepsilon_{y f, t} & =0.7840 \varepsilon_{y f, t-1}+\eta_{y f, t}, \sigma_{y f, t}=0.0430
\end{aligned}
$$

\section{Appendix 3: Calibration}

The calibrated parameters are taken from Millard (2011). The paramters are split into two groups, with the first group of parameters being the set that are important in deriving the model's steady state, derived by taking average ratios, with little or no influence on the dynamics properties. They are set to match steady-state values in Harrison et al. (2011), except elasticity of demand for differentiated labour that is in the second category of parameters. When I estimate the model, these sets of parameters are fixed, hence, the name: fixed parameters shown in Fig. 11 below.

The second set of parameters are priors used in Millard (2011). The prior for the parameter on inflation in Taylor's rule is in line with Taylor's original paper. This is the set that we will estimate in the study using indirect inference testing. This set of parameters as estimated parameters is shown in Table 4. The value of the capital adjustment cost is set at 201 is justified from Eq. (21), in the "Appendix". It shows how capital costs gives incentives for households to change the capital stock slowly (Harrison and Oomen 2010). This means that a higher adjustment cost parameter, $\chi_{z}$, will decrease the change elasticity in capital stock with regards to interest rate, shadow price of capital and the capital rental rate (Tables 9,10$)$.
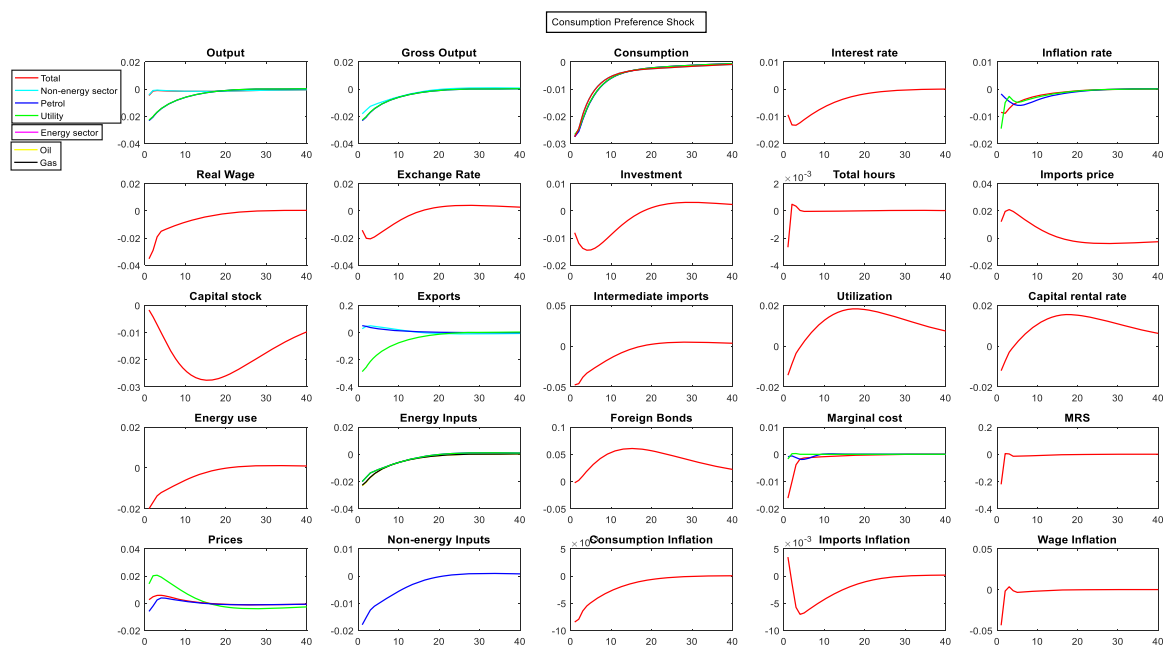

Fig. 11 Consumption preference shock 
Table 9 Fixed parameters

\begin{tabular}{|c|c|c|}
\hline & Value & Parameter description \\
\hline$\beta$ & 0.9925 & Discount factor \\
\hline$\chi_{b f}$ & 0.001 & Cost of adjusting portfolio of foreign bonds \\
\hline$\delta$ & 0.013 & Depreciation rate \\
\hline$\chi_{z}$ & 0.0206 & Scales the effect of capital \\
\hline$\sigma_{e}$ & 0.4 & $\begin{array}{l}\text { Elasticity of substitution between non-energy and energy in } \\
\text { consumption }\end{array}$ \\
\hline$\sigma_{p}$ & 0.1 & $\begin{array}{l}\text { Elasticity of substitution between petrol and utilities in energy } \\
\text { consumption }\end{array}$ \\
\hline$\sigma_{v}$ & 0.5 & Elasticity of substitution between labour and capital in value-added \\
\hline$\sigma_{q}$ & 0.15 & $\begin{array}{l}\text { Elasticity of substitution between energy and everything else in } \\
\text { non-energy }\end{array}$ \\
\hline$\psi_{e}$ & 0.0526 & Share of energy in consumption \\
\hline$\psi_{p}$ & 0.5913 & Share of petrol in energy consumption \\
\hline$\alpha_{q}$ & 0.0528 & Cost share of energy in non-energy gross output \\
\hline$\alpha_{B}$ & 0.3154 & Cost share of imports in 'bundle' \\
\hline$\alpha_{v}$ & 0.1701 & Cost share of capital in value-added \\
\hline$\psi_{n}$ & 0.3096 & Cost share of petrol in energy output \\
\hline$\psi_{q p}$ & 0.1844 & Cost share of value-added in petrol output \\
\hline$\psi_{u}$ & 0.4834 & Cost share of value-added in utilities output \\
\hline$\psi_{d}$ & 0.617 & Share of duty in petrol prices \\
\hline$\frac{c_{n}}{p_{c} c}$ & 0.9474 & Share of non-energy consumption in total consumption \\
\hline$\frac{p_{u} c_{u}}{p_{c} c}$ & 0.0215 & Share of utility consumption in total consumption \\
\hline$\frac{V_{n}}{V}$ & 0.9815 & Share of value-added used as input in non-energy goods \\
\hline$\frac{V_{u}}{V}$ & 0.0145 & Share of value-added used as input in utilities \\
\hline$\frac{c_{p}}{q_{p}}$ & 0.4202 & Share of petrol output going to consumption \\
\hline$\frac{c_{u}}{q_{u}}$ & 0.4054 & Share of utilities output going to consumption \\
\hline$\frac{X_{O}}{I_{O}}$ & 0.4551 & Ratio of oil exports to oil inputs \\
\hline$\frac{X_{g}}{I_{g}}$ & -0.0792 & Ratio of gas exports to gas inputs \\
\hline$\frac{c_{n}}{q}$ & 0.5801 & Share of private consumption in non-energy output \\
\hline$k / q$ & 4.7202 & Ratio of capital to non-energy gross output \\
\hline$\frac{x_{n}}{q}$ & 0.2552 & Share of exports in non-energy gross output \\
\hline$\frac{M_{n}}{q}$ & 0.2581 & $\begin{array}{l}\text { Ratio of imports of non-energy goods to gross output of non-energy } \\
\text { goods }\end{array}$ \\
\hline$\frac{X_{O}}{q}$ & 0.0035 & Ratio of oil exports to gross output of non-energy goods \\
\hline$\frac{X_{g}}{q}$ & -0.0007 & Ratio of gas exports to gross output of non-energy goods \\
\hline
\end{tabular}


Table 10 Parameters to be estimated

\begin{tabular}{lll}
\hline & Parameter description & Value \\
\hline$\theta_{y}$ & Taylor Rule Coefficient on output & 0.125 \\
$\varepsilon_{p}$ & Degree of indexation: non-energy sector & 0.5 \\
$\chi_{p}$ & Probability of not being able to change price: non-energy sector & 0.5 \\
$\varepsilon_{p m}$ & Degree of Indexation: importers & 0.5 \\
$\xi_{p m}$ & Probability of not able to change price: importers & 0.5 \\
$\eta_{x}$ & Elasticity of demand for exports & 1.5 \\
$\psi_{z}$ & Degree of persistence in export demand & 0.5 \\
$\psi_{h a b}$ & Degree of habit persistence in consumption & 0.5 \\
$\sigma_{c}$ & Intertemporal elasticity of substitution & 0.66 \\
$\varepsilon_{k}$ & Degree of persistence in investment adjustment costs & 0.5 \\
$\psi_{w}$ & Probability of being able to change wages & 0.5 \\
$\xi_{w}$ & Degree of wage indexation & 0.5 \\
$\sigma_{h}$ & Frisch elasticity of labour supply & 0.43 \\
$\theta_{r g}$ & Degree of Taylor-rule interest-rate smoothing & 0.5 \\
$\theta_{p d o t}$ & Taylor rule coefficient on inflation & 1.5 \\
$\chi_{k}$ & Scale of capital adjustment cost & 201 \\
$\psi_{w c}$ & Share of wage bill paid financed by borrowing & 0.5 \\
$\chi_{u}$ & Probability not being able to change price: utility & 0.5 \\
$\chi_{p p}$ & Probability not being able to change price: petrol & 0.5 \\
$\varepsilon_{u}$ & Degree of indexation: utilities sector & 0.5 \\
$\varepsilon_{p p}$ & Degree of indexation: petrol sector & 0.5 \\
$\phi_{z}$ & Inverse elasticity of capital utilisation costs & 0.56 \\
$\sigma_{w}$ & Elasticity of demand for differentiated labour & 3.8906 \\
\hline & &
\end{tabular}

\section{Appendix 4: Impulse Response Function of the Structural Model}

The impulse responses come from positive shocks of each of the twelve exogenous shocks in the model that are assumed to follow AR(1) processes. The figures here are shown using the model's estimated parameters. In each figure, the $y$-axis refers to percentage change of a variable against steady state value in response to a shock while the $x$-axis refers to 'quarters' as the shocks are presumed to occur in the first quarter where I use dynare to generate the IRFs. Energy sector here refers to combination of petrol and utilities output where consumption such is considered.

Figure 11 shows the effect a $15 \%$ consumption preference ${ }^{18}$ shock has on the real macroeconomic aggregates. This shock is similar to an increase in risk premium such as credit control, and this will result in a fall in aggregate consumption, inflation, and output. To meet higher demand, the firm raises capacity utilization and employment as both are falling. The effect of falling consumption is also reflected in falling consump-

18 This is a shock that will increase the interest rate aimed at the consumers in relation to the policy rate. 

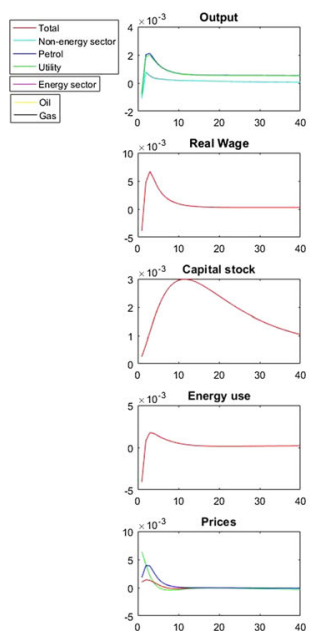
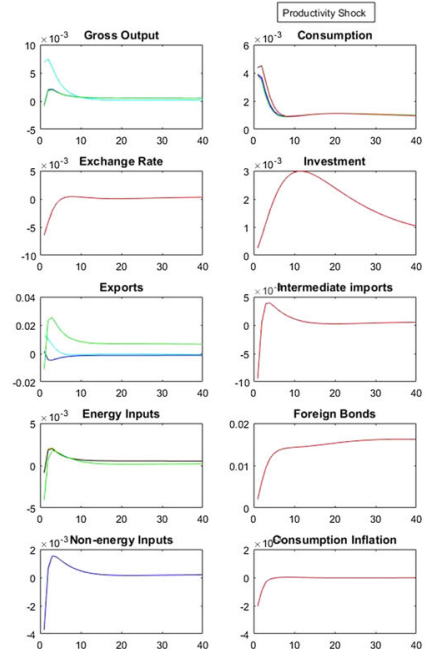
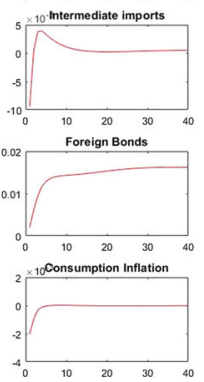
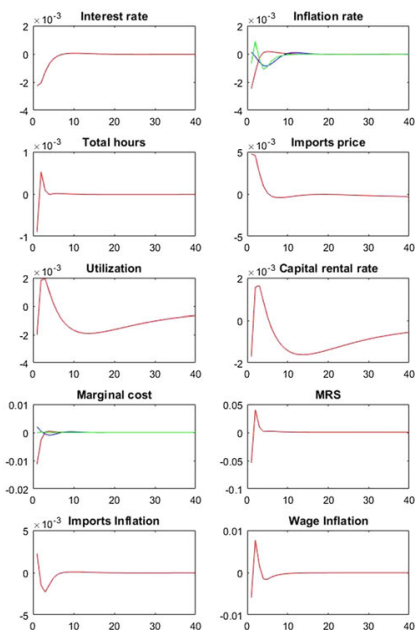

Fig. 12 Productivity shock

tion inflation as consumer confidence is low. The response in falling real wages shows the willingness to work by households so that they can earn more to make purchases and also because of wage stickiness. However, the exchange rate rises as a response to the shock as demand falls in the UK relative to prices abroad. The movement in foreign bonds comes through in the foreign interest rate shock, hence foreign risk premium. The shock response to inflation and interest rates falling are as a result of flexible prices and central bank's Taylor rule.

Figure 12 show the response of the model variables to a one standard deviation productivity shock. The productivity shock affects non-energy gross output given value-added input (a fraction of total value-added that is proxy of output in this model) as it drives it to rise by almost $0.75 \%$. As we can see, surprisingly, output fall that causes the fall in employment and capital utilization as aggregate demand does not correspond to output. This the makes marginal cost to increase for all firms as they respond by lowering prices to stimulate aggregate demand by reducing total hours and demand for capital. As a result of the shock, investment falls immediately but recovers within the year so that capital stock could be built up. The response by investment is due to the impact of capital adjustment costs. Assuming sticky prices, the demand for non-energy gross output will not respond much to the increase in productivity, which makes producers cut down on inputs, and this will include value-added. Also, assuming sticky wages, there will be a 'knock-on' effect on total hours of work. Consumption will rise while the shock makes households richer. Annual inflation and interest rates will fall and exchange rate depreciates as goods inside the UK will be produced at a lower cost compared to foreign goods.

Figure 13 shows the effects of a positive unit government spending shock. This shock leads to a fall in consumption which reflects 'crowding-out' effect (because increase in government spending is usually financed by higher lump-sum taxes from households). The overall effect is a positive one as firms demand more labour for 2 quarters and increase capacity utilization. The rental rate of capital rises as does 

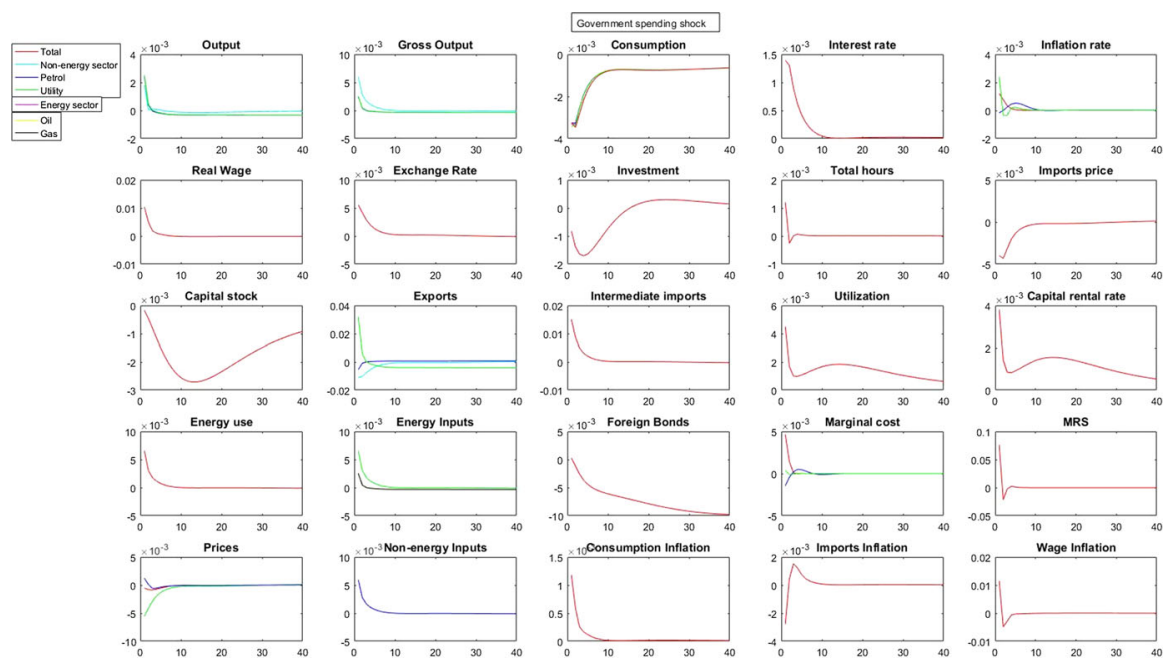

Fig. 13 Government spending shock
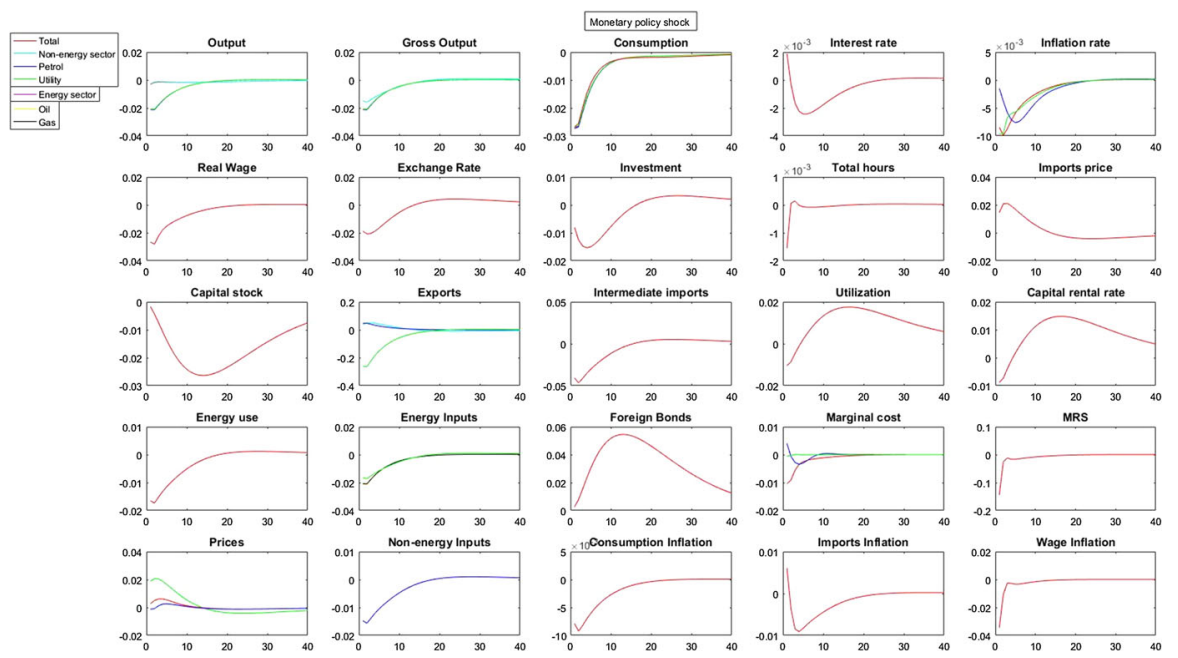

Fig. 14 Monetary policy shock

real wage rate because of households' willingness to work more. Although the rise in output is much smaller than the increase in government spending, the increase in demand leads to a rise in inflation, though this is close to zero, and also gave a little push to the interest rates as the Bank of England moves to cut demand. Finally, the increase in exogenous government spending relative to foreign demand pushes the exchange rate that appreciates.

Figure 14 shows the responses of model variables to a standard deviation monetary policy shock. Following this shock, the short-term and real interest rate will rise. Reflecting the role of nominal rigidities, the increase in rates causes a fall in consump- 

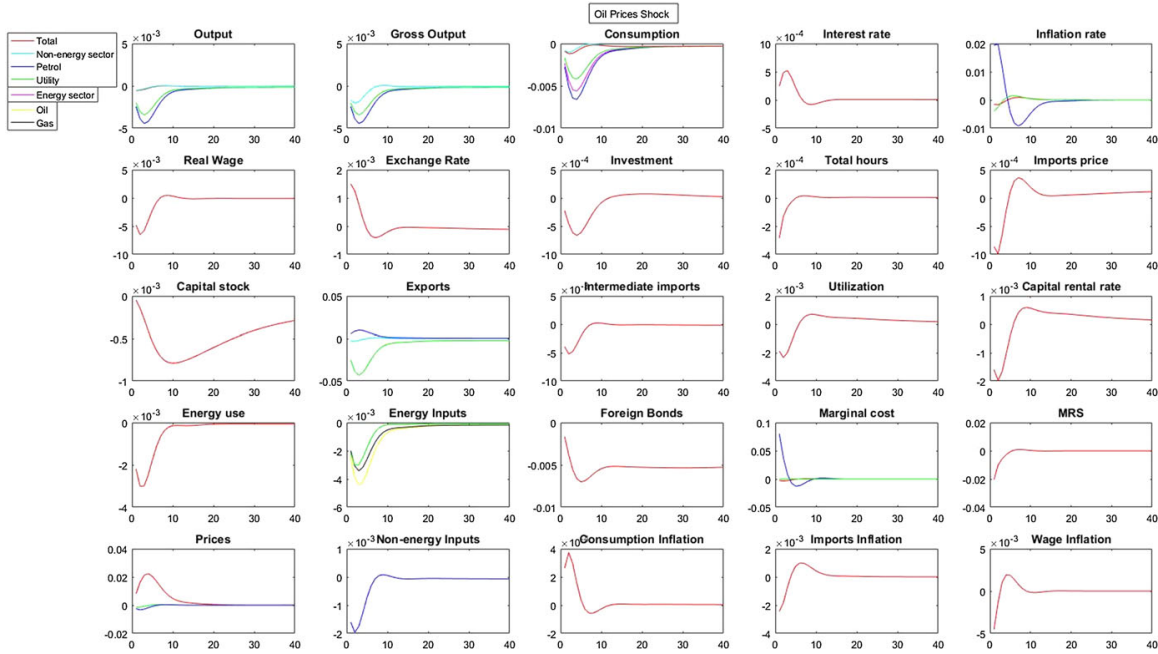

Fig. 15 Oil prices shock

tion, the output is affected negatively as it falls, as well as an investment. The fall in investment will about twice as that of output. Firms will also reduce employment while the rate of utilization of capital will fall due to lower aggregate demand. Oil exports rise significantly while foreign demand for gas goes the other way as a result of the shock. Petrol prices after tax fall as a result of the rise in interest rate that shows the maximum response of real variables to the shock is instantaneous. The exchange rate tracks interest rate's pattern; this is because of uncovered interest rate parity (UIP) condition with the initial effect of the shock being an appreciation. The appreciation of exchange rates comes with the increase in interest rate. Domestic sticky prices will lead to rise in exchange rates, and this will consequently reduce the demand for exports. There is a fall in real wages as demand falls, and households are willing to work due to fall in inflation across sectors will returns to steady-state after about three and a half years. The responses here are in line with the empirical study of di Cecio and Nelson (2007), Kamber and Millard (2010) and Christiano et al. (2005).

This model is developed precisely to evaluate the effects of a standard deviation shock to world energy prices. Therefore, it is most important to study the impact of the shock to world oil prices.

Figure 15 shows the responses of variables to an exogenous increase in the oil prices shock of $12.7 \%$ (one standard deviation shock). The effects of the shock have output and consumption falling but converges within five and ten quarters respectively. The effects of this shock are minimal as can is seen in proportion to the shock. Generally, energy price shock is argued to be less effective in DSGE models (Hamilton 2003; Kilian and Vigfusson 2014). The effects, on falling output, are only a temporary terms of trade shock. As GDP only falls briefly, the UK can borrow against such a temporary fall. This effect comes as exchange rates rise which makes a demand for foreign goods fall, hence a drop in demand for intermediate imports in the model. The marginal cost of producing petrol increases as firm's demand less of labour to reduce that, output 

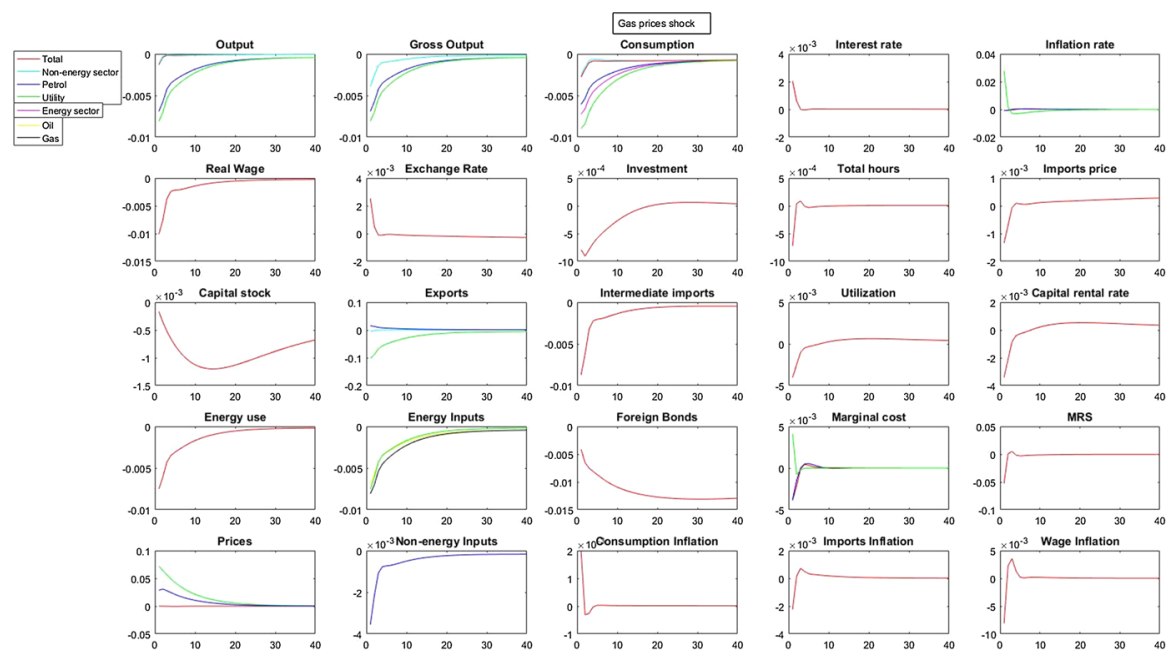

Fig. 16 World gas price shock

falls. Inflation is decreasing and then rises above its steady-state as a response to the shock. Labour takes a hit in their real wage for a five quarters following the shock which means there is a slight indication of real wage resistance. Figure 16 shows the responses of real variables to an exogenous increase in the world price of gas of $7.4 \%$ (a one standard deviation shock). The effects of this shock are qualitatively similar to those of an oil price shock. The effects on real variables are, again small this is because the shock has low persistence. The impact of the shock have output and consumption falling consumption. Inflation of the sector rises above its steady-state as a response to the shock. Labour takes a hit in their real wage for a few quarters following the shock which means there is a slight indication of real wage resistance.

\section{References}

Boldrin, M., Christiano, L. J., \& Fisher, J. (2001). Habit persistence, asset returns, and the business cycle. American Economic Review, 91, 149-166.

Canova, F. (1995). Sensitivity analysis and model evaluation in simulated dynamic general equilibrium economies. International Economic Review, 36, 477-501.

Canova, F. (2005). Methods for applied macroeconomic research. Princeton: Princeton University Press.

Chaudhuri, K., \& Daniel, B. C. (1998). Long-run equilibrium real exchange rates and oil prices. Economics Letters, 58, 231-238.

Christiano, L. J., Eichenbaum, M., \& Evans, C. (2005). Nominal rigidities and dynamic effects of a shock to monetary policy. Journal of Political Economy, 113, 1-45.

Clarida, R., Gali, J., \& Gertler, M. (1999). The science of monetary policy: A new keynesian perspective. Journal of Economic Literature, 37(4), 1661-1707.

De Miguel, C., Manzano, B., \& Martin-Moreno, J. M. (2003). Oil price shocks and aggregate fluctuations. Energy Journal, 24(2), 47-61.

Faccini, R., Millard, S. P., \& Zanetti F. (2011). An estimated DSGE model of the UK labour market. Bank of England working paper no. 408, London.

Finn, M. (1995). Variance properties of Solow's productivity residual and their cyclical implications. Journal of Economic Dynamics and Control, 19, 1249-1281. 
Hamilton, J. D. (2003). What is an oil shock? Journal of Econometrics, 113(2), 363-398.

Hamilton, J. D. (2009). Causes and consequences of the oil shock of 2007-2008. In Brookings papers on economic activity. Economic Studies Program, The Brookings Institution, (vol. 40 (1 (Spring), pp. 215-283).

Harrison, R., \& Oomen, O. (2010). Evaluating and estimating a DSGE model for the United Kingdom. Bank of England working paper no. 380, London.

Harrison, R., Thomas, R., \& de Weymarn, I. (2011). The impact of permanent energy price shocks on the UK economy. Bank of England working paper no. 433, London.

Ingber, L. (1996). Adaptive simulated annealing (ASA): Lessons learned. Lester Ingber Papers 96as, Lester Ingber.

Jiménez-Rodríguez, R., \& Sánchez, M. (2005). Oil price shocks and real GDP growth: Empirical evidence for some OECD countries. Applied Economics, 37, 201-228.

Kamber, G., \& Millard, S. P. (2010). Using estimated models to assess nominal and real rigidities in the United Kingdom. Bank of England working paper no. 396, London.

Kilian, L. (2008). The economic effects of energy price shocks. Journal of Economic Literature, 46(4), 871-909.

Kilian, L., \& Vigfusson, R. J. (2014). The role of oil price shocks in causing U.S. recessions. Working paper series 460, Center for Financial Studies (CFS).

Kim, I.-M., \& Loungani, P. (1992). The role of energy in real business cycle models. Journal of Monetary Economics, 29, 173-89.

Le, V. P. M., Minford, P., \& Wickens, M. (2009). The 'puzzles' methodology: En route to Indirect Inference? Economic Modelling, 27(6), 1417-1428.

Le, V. P. M., Meenagh, D., Minford, P., \& Wickens, M. (2012). Testing DSGE models by Indirect inference and other methods: Some Monte Carlo experiments. Cardiff Economics working paper E2012/15, Cardiff University, Cardiff Business School.

Le, V. P. M., Minford, P., \& Wickens, M. (2013). A Monte Carlo procedure for checking identification in DSGE models. CEPR discussion papers 9411. C.E.P.R. discussion papers.

McCallum, B. (1976). Rational expectations and the estimation of econometric models: An alternative procedure. International Economic Review, 17(2), 484-490.

Meenagh, D., Minford, P., \& Theordoridis, K. (2009). Testing a model of the UK by the method of indirect inference. Open Economies Review, 20(2), 265-291.

Meenagh, D., Minford, P., \& Wickens, M. (2012). Testing macroeconomic models by indirect inference on unfiltered data. Cardiff Economics working papers E2012/17, Cardiff University, Cardiff Business School.

Millard, S. P. (2011). An estimated DSGE model of energy, costs and inflation in the United Kingdom. Bank of England working paper no. 432, London.

Nordhaus, W. D. (1980). The energy crisis and macroeconomic policy. The Energy Journal, International Association for Energy Economics, vol. 0(Number 1).

Rebelo, S. (2005). Real business cycle models: Past, present and future. Scandinavian Journal of Economics, 107(2), 217-238, 06 .

Rotemberg, J., \& Woodford, M. (1996). Imperfect competition and the effects of energy price increases on economic activity. Journal of Money, Credit and Banking, 28, 549-77.

Smets, F., \& Wouters, R. (2003). An estimated dynamic stochastic general equilibrium model for the euro area. Journal of the European Economic Association, 1, 1,123-75.

Smets, F., \& Wouters, R. (2007). Shocks and frictions in US business cycles: A Bayesian approach. American Economic Review, 97, 586-606.

Wickens, M. R. (1982). The efficient estimation of econometric models with rational expectations. Review of Economic Studies, 49, 55-67. 